\title{
SAFETY EVALUATION OF SIGNALIZED INTERSECTIONS \\ WITH AUTOMATED VEHICLES AT VARIOUS PENETRATION LEVELS \\ BASED ON CONFLICT ANALYSIS OF SIMULATED TRAFFIC
}

\author{
By \\ Maria Espinosa \\ Bachelor of Engineering, Ryerson University, Toronto, Canada, 2015
}

\author{
A Thesis \\ presented to Ryerson University \\ in partial fulfillment of the \\ requirements for the degree of \\ Master of Applied Science \\ in the Program of \\ Civil Engineering
}

Toronto, Ontario, Canada, 2017

(C) Maria Espinosa 2017 


\section{Author's Declaration}

I hereby declare that I am the sole author of this thesis. This a true copy of the thesis, including any required final revisions, as accepted by my examiners.

I authorize Ryerson University to lend this thesis to other institutions or individuals for the purpose of scholarly research.

I further authorise Ryerson University to reproduce this thesis by photocopying or by other means, in total or in part, at the request of other institutions or individuals for the purpose of scholarly research.

I understand that my thesis may be made electronically available to the public. 


\title{
SAFETY EVALUATION OF SIGNALIZED INTERSECTIONS \\ WITH AUTOMATED VEHICLES AT VARIOUS PENETRATION LEVELS \\ BASED ON CONFLICT ANALYSIS OF SIMULATED TRAFFIC
}

\author{
By \\ Maria Espinosa \\ Department of Civil Engineering \\ Ryerson University \\ Master of Applied Science, 2017
}

\begin{abstract}
Automated vehicles (AVs) are expected to offer great benefits by potentially reducing crashes. The safety at signalized intersections is influenced by several factors, one of them being the driving behavior. By introducing AVs on the roads, the unpredictability of this factor will potentially decrease and eventually, reduce crashes. By using microsimulation, it was possible to use simulated traffic conflicts as indicators of potential crashes, to analyze the potential safety of signalized intersections in the presence of automated vehicles. The objective was to compare crash frequency for signalized intersections at various AVs penetration levels $(0 \%, 50 \%$ and $100 \%)$ by using prediction models that relate crashes to conflicts. Furthermore, the effect on crashes of introducing hypothetical left turn treatments was also evaluated. The results indicated that intersection safety may improve in the presence of AVs. However, the safety effects of treatments may be reduced compared to the effects with no AVs.
\end{abstract}




\section{Acknowledgements}

I would first like to thank my supervisor Dr. Bhagwant Persaud for all the financial and educational support throughout my study.

I would also like to thank my colleague Taha Saleem for all the help provided with the software and the data used in this thesis.

Finally, I would like to thank my family and my friends for their support. To my uncle who inspired me to pursue my masters. To my mom and my sister for their encouragement and continuous support during these two years. To Caden for all his love and patience through the process of writing this thesis. 


\section{Table of Contents}

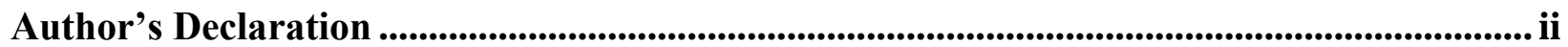

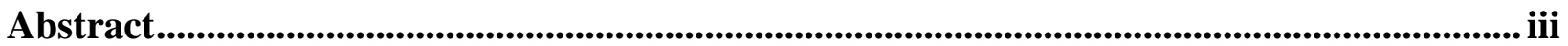

Acknowledgements ......................................................................................................................... iv

Table of Contents ............................................................................................................................................ v

List of Tables ...................................................................................................................................... vii

List of Figures...................................................................................................................... vii

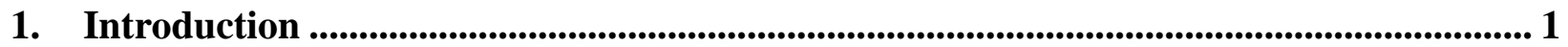

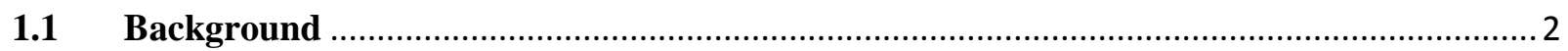

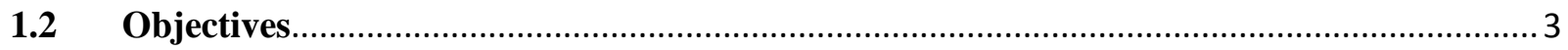

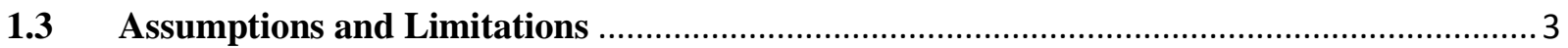

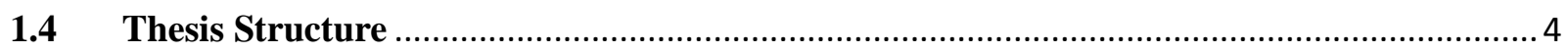

2. Literature Review .......................................................................................................................... 6

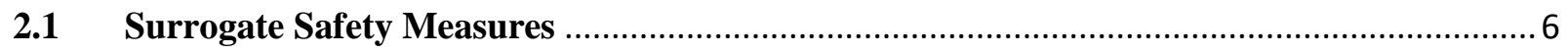

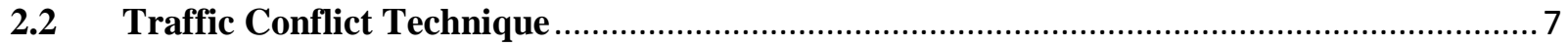

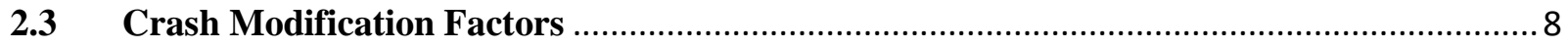

2.4 Intelligent Transportation Systems ………………………………………………... 8

2.4.1 Automated Vehicles .....................................................................................

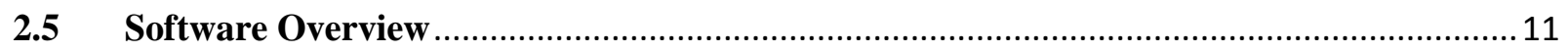

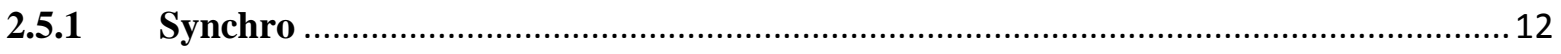

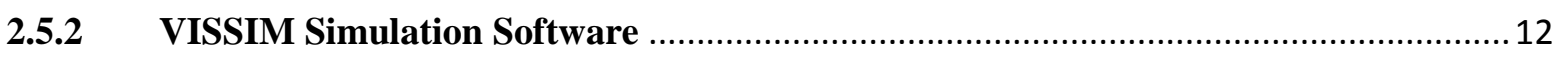

2.5.3 Surrogate Safety Assessment Model (SSAM) ………………………………...... 15

3. Methodology .............................................................................................................................. 18

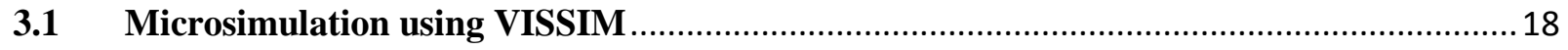

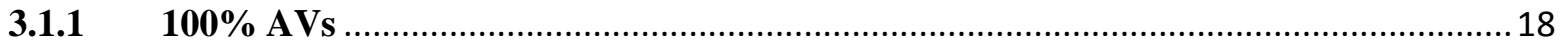

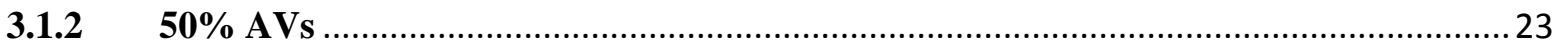

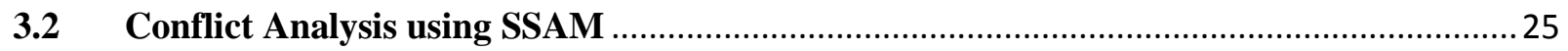

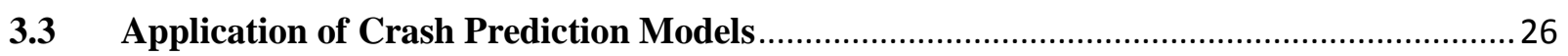

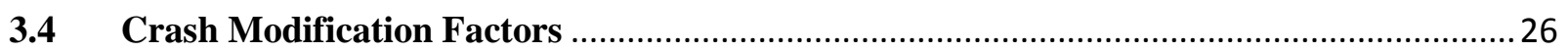

3.5 Evaluation of Safety Treatments for Signalized Intersections .........................................2 26 
4. Summary of Data and Crash Prediction Models Used .......................................................... 28

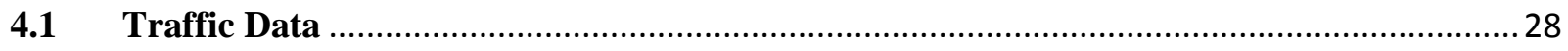

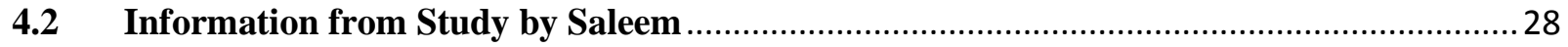

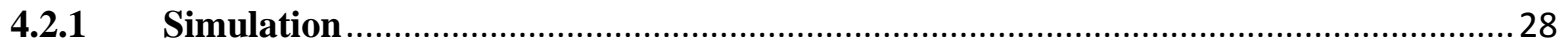

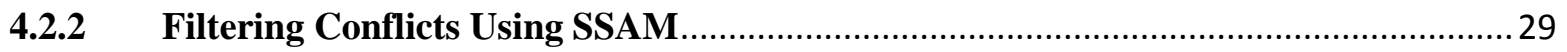

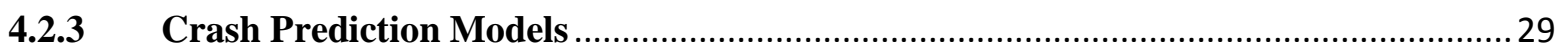

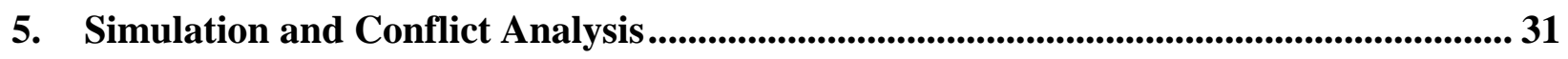

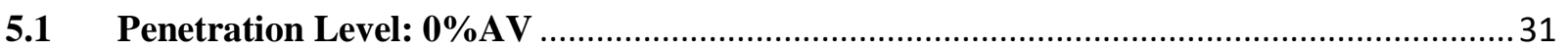

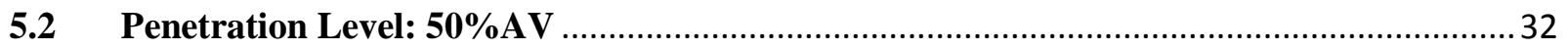

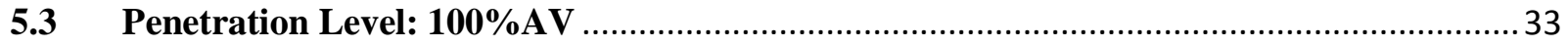

6. Crash Prediction and Evaluation ............................................................................................... 34

7. Crash Modification Factors (CMFs) for Introducing AVs......................................... 36

8. Crash Modification Factors for a Safety Treatments in the Presence of AVs ................ 38

8.1 Safety Treatment: Left turn phasing improvement...................................................... 38

8.1.1 Simulation and Conflict Analysis ...................................................................... 38

8.1.2 Crash Prediction Before and After Safety Treatment ............................................ 40

8.1.3 Crash Modification Factors for Left Turn Phasing Improvement ............................ 41

8.2 Safety Treatment: Introduction of Exclusive Left Turn..................................................... 44

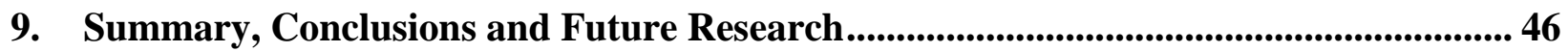

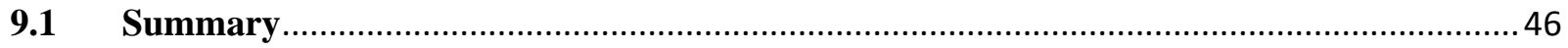

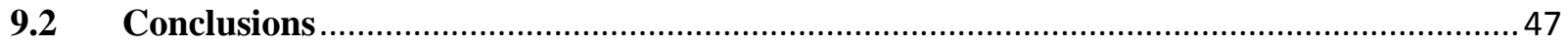

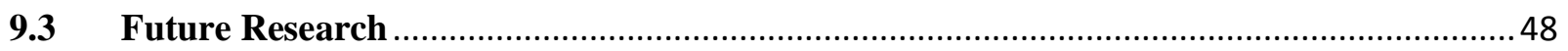

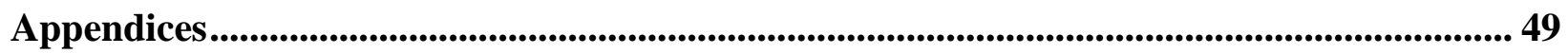

Appendix A: Statistics of Predicted Crashes for Three Penetration Levels ................................ 49

Appendix B: Comparison of Conflicts Before and After Safety Treatment ................................ 51

Appendix C: CMF Ranges After Applying Safety Treatment ................................................... 52

References............................................................................................................................................ 53 


\section{List of Tables}

Table 1: Top 8 Causative Factors for Commercial Vehicle Crashes in

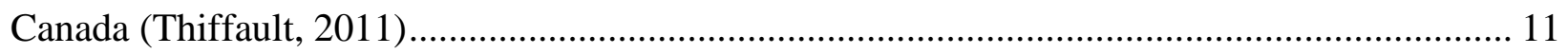

Table 2:Wiedemann 99 Model Parameters (PTV, 2011)........................................................ 15

Table 3: Description of Surrogate Conflict Measures (Gettman, Pu, Sayed, \& Shelby, 2008).... 16 Table 4: Parameters for Crash Models Based on Simulated Traffic (Saleem, Persaud, Shalaby, \&

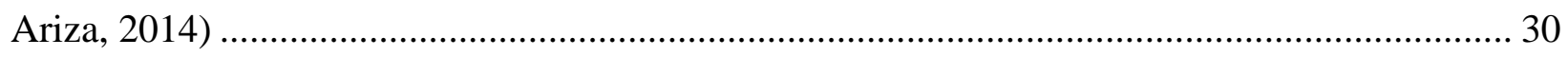

Table 5: Estimated Conflicts for Sites with 0\%AV ………………………………………......... 31

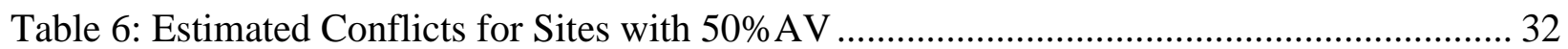

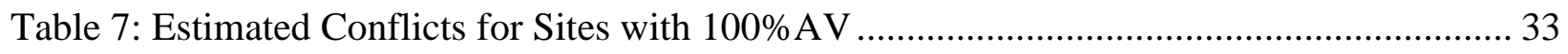

Table 8: Mean crashes per year at various penetration levels ..................................................... 35

Table 9: Summary of CMFs by crash model ........................................................................... 36

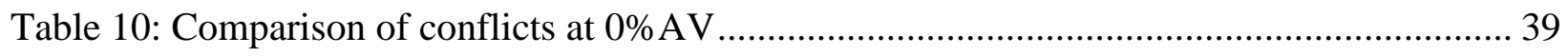

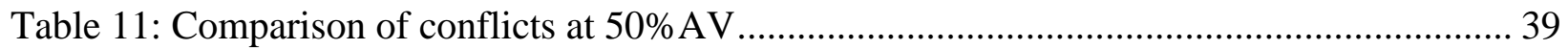

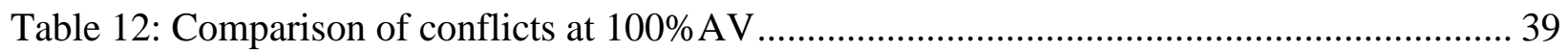

Table 13: Predicted crashes per year BEFORE safety treatment .................................................. 41

Table 14: Predicted crashes per year AFTER safety treatment .................................................... 41

Table 15: Estimated CMFs for safety treatment .................................................................... 42

Table 16: Comparison of calculated CMFs to those obtained from Saleem (2012)..................... 43

Table 17: Estimated crashes and average CMF for addition of exclusive left turn ....................... 45 


\section{List of Figures}

Figure 1: The safety pyramid (Hydén, 1987; Svensson, 1998) ............................................... 7

Figure 2: Predictability of Driver Behaviour (Althoff, Stursberg, \& Buss, 2009) ................... 11

Figure 3: Driving Behaviour - Wiedemann 74 (PTV, 2011) ................................................ 13

Figure 4: Driving Behaviour - Wiedemann 99 (PTV, 2011) ............................................... 14

Figure 5: Angle Classification Diagram used in SSAM ................................................. 17

Figure 6: Driving Behaviour for AVs (Car-following) ..................................................... 20

Figure 7: Driving Behaviour for AVs (Lane Change) .................................................... 21

Figure 8: Vehicle Composition for 100\% Penetration Level of AVs ..................................... 22

Figure 9: Sample of Vehicle Routes in VISSIM ............................................................ 23

Figure 10: Vehicle Composition for 50\%AVs ................................................................ 24

Figure 11: Static Vehicle Routes for 50\%AV scenario ..................................................... 25 


\section{Introduction}

As new technologies are developed, the world of road safety stays up to date by innovating and applying new ways for crash prevention. An example of these new types of technology is automated vehicles (AVs). The National Highway Traffic Safety Administration (NHTSA), defines them as vehicles that do not require direct driver input to control certain operations such as steering, acceleration and braking (U.S. Department of Transportation, 2013), and by doing so, potentially reducing $94 \%$ of crashes commonly caused by human choice error (Rosekind, 2016).

AVs are characterized for their ability to communicate with other vehicles as well as with infrastructure. This is evident through intelligent cruise control as well cooperative driving systems (Kun \& Petros, 2004). As a result of these unique features, AVs have their own driving behaviour. Hence, the possibility for driver distraction is reduced due to the AVs predictability.

Intersection-related crashes make up about $23 \%$ of fatal crashes of the overall highway system, out of which $6 \%$ occur at signalized intersections (NCHRP, 2004). The fatality rate in Toronto due to motor vehicle collisions in 2013 was the highest in all of Canada, with $33 \%$ of all crashes occurring at signalized intersections (City of Toronto, 2013).

To understand the impact on signalized intersections when introducing automated vehicles from the point of view of road safety, it is necessary to perform a safety evaluation. In this case, it will be based on conflict analysis since there is no real-world data yet for AV safety performance. A conflict can be defined as a near-collision event where two vehicles that interact with each other perform maneuvers to avoid a crash.

By using a microscopic traffic simulation software and altering driving behaviour parameters, it was possible to model how AVs, at different penetration levels, would behave at various signalized intersections across Toronto. 


\subsection{Background}

In Canada, road safety is considered a public health matter due to the high number of mortality and injuries caused by motor vehicle collisions (Transport Canada, 2011). Leading causes of crashes have been attributed to impaired driving, speeding and human error (i.e. insufficient reaction time to avoid a collision). According to the National Highway Traffic Safety Administration, a study from 2009 demonstrated that around 36\% of crashes resulting in fatalities and injuries involved a driver distraction (NHTSA, 2010). Many studies have been performed to decrease these numbers by providing improvements and adding new technologies to the city's infrastructure. One of these new technologies is automated vehicles.

$\mathrm{AVs}$ are characterized for their ability to communicate with other vehicles using intelligent cruise control and cooperative driving systems (Kun \& Petros, 2004). These unique features allow AVs to have a distinct driving behaviour. This new predictable driving behaviour creates the possibility to reduce human error and distraction.

There are many strategies to improve safety at signalized intersections such as operational analysis (assigning right-of-way), geometric design (separating through and turning movements), infrastructure assessment (improving pavement conditions) and traffic control (obeying speed limits). Several studies have shown that the introduction of automated vehicles will contribute to a reduction of crashes on the roads. KPMG (2012) promotes a goal of having "crash-less" cars that will reduce crashes by almost 90\%; Hayes (2011) suggests that the rate of fatal crashes could eventually match the rates of about $1 \%$ usually seen in rail and aviation. However, it is important to be aware that all studies are hypothetical since there is no actual data to verify outcomes.

Road safety studies involving evaluation and improvement of roads are mostly based on historical crash data obtained from reported crashes (Saleem, 2012). However, minor crashes have the tendency to go unrecorded if the damage falls below the minimum damage threshold based on the Highway Traffic Act. For this reason, traffic conflicts are used as a measure of safety (Saleem, 2012).

This research analyzes and explores the safety effects on signalized intersections of introducing $\mathrm{AVs}$ in the City of Toronto based on the number of conflicts obtained at various penetration levels from simulated traffic. Due to the lack of crash database for AVs, conflicts generated from 
simulated traffic and crash-conflict prediction models developed by Saleem (2012), that were based on similar intersections, are used to predict crashes.

\subsection{Objectives}

The main purpose of this study is to perform a safety evaluation of signalized intersections when automated vehicles and safety treatments are introduced at various penetration levels. This is achieved by using crash prediction models and conflict analysis of simulated traffic. Accordingly, the major tasks of this thesis work are:

- Obtain acceptable test data for the research.

- Simulate automated vehicles using VISSIM software at three penetration levels $(0 \% \mathrm{AV}$, $50 \% \mathrm{AV}$ and $100 \% \mathrm{AV}$ ) for 78 signalized intersections in the city of Toronto

- Identify conflicts within simulation outputs by using surrogate conflict measures.

- Apply crash-conflict prediction models based on conflicts to 78 signalized intersections.

- Calculate crash modification factors for each model applied to 78 intersections.

- Evaluate the safety effects of introducing automated vehicles based on crash modification factors.

- Explore the effects for each penetration level of hypothetical left turn treatments applied to intersections where such treatments might be considered, by performing a before-and-after comparison to calculate crash modification factors.

\subsection{Assumptions and Limitations}

Since automated vehicles are an ongoing research topic, it is not possible to simulate AVs accurately at this time. Due to this limitation, the following assumptions were considered for this study:

- All simulations are assumed to have normal road and weather conditions.

- It is assumed that the level of automation for all automated vehicles is the same: Level 3 according to NHTSA and SAE (Ticoll, 2015). 
- For the two penetration levels involving automated vehicles and non-automated vehicles, (50\% scenario), trucks were always kept as fully automated.

- This study does not show communication of vehicles with infrastructure (i.e. traffic lights). But it does replicate vehicle-to-vehicle communication by adjusting the driving behaviour parameters.

- The values of the simulation parameters used to replicate the driving behaviour of AVs are based on the latest research and these are assumed to be reasonable.

- The values used to replicate the driving behaviour of non-automated vehicles are based on previous research by Saleem (2012), from which the original data and crash-conflict prediction models were obtained for this study. These values are assumed to be reasonable.

- The desired speed distribution for AVs is assumed. Since automated vehicles are able to communicate with their close surroundings (other vehicles), it is assumed that all vehicles will go to the maximum allowed speed to maintain the traffic flow constant.

- Calibration of simulation in the presence of AVs is not possible due to the lack of crash data.

Justification regarding the previously mentioned assumptions will be provided throughout this thesis.

\subsection{Thesis Structure}

This thesis is comprised of 9 chapters. The first chapter presents an introduction and background information about road safety of signalized intersection in Canada, as well as an introduction of how automated vehicles could potentially reduce crashes. It also contains the objectives, assumptions and the structure that this thesis follows.

Chapter 2 provides a literature review of previous research areas that support the development of this thesis. The five areas are the definition of surrogate safety measures, description of the traffic conflict technique, crash modification factors and their relationship to safety, rationale of intelligent transportation systems, specifically automated vehicles and a software overview. 
Chapter 3 focuses on the methodology and the steps taken to achieve the main objectives. This chapter explains the creation of a new driving behaviour, simulations runs and estimation of conflicts that are used to apply the crash prediction models and crash modification factors.

Chapter 4 presents a general overview of the data used for this research and the criteria used to select the sites. Since this study is based on former research performed by Saleem (2012), this chapter explains all the processes used to filter traffic data and develop crash-conflict prediction models used in this study.

Chapter 5 describes the results and findings of the first part of this study: simulation and analysis of conflicts. This section is divided into three subsections, which provide a more detailed explanation of outcomes at each penetration level.

Chapter 6 outlines results for the predicted crashes at each penetration level using conflicts previously analyzed.

Chapter 7 interprets the predicted crashes in Chapter 6 by calculating crash modification factors. The CMFs are calculated with the respect to predicted crashes of the untreated site $(0 \% \mathrm{AV})$ and the predicted crashes after a countermeasure $(50 \% \mathrm{AV}$ and $100 \% \mathrm{AV})$ has been applied.

Chapter 8 discusses the results of changing a permissive left turn signal to protected-permissive turn in 13 of the 78 signalized intersections; as well as introducing an exclusive left turn to 11 of the 78 signalized intersections. It compares the results obtained in these safety treatments with the ones previously estimated for all three-penetration levels. Moreover, it compares the results obtained in the study by Saleem (2012) to the outcome obtained in this study for the 0\%AV penetration level for the improvement of the left turn phasing.

Finally, Chapter 9 contains the summary and conclusions of this research study. Additionally, it provides a description of future research related to this topic. 


\section{Literature Review}

This chapter outlines five main areas of previously published literature on topics relevant to this research. These topics include surrogate safety measures, traffic conflict technique, crash modification factors, intelligent transportation systems and a software overview.

\subsection{Surrogate Safety Measures}

As previously mentioned, road safety studies tend not to use crash data for analysis due to many unreported accidents and inadequate sample sizes, which creates limitations to the research and may provide inaccurate results. For this reason, other traffic indicators correlated to crashes have been developed. These indicators are defined as a quantifiable observation as a supplementary element to crash data (Thompson \& Perkins, 1983) and are accordingly named surrogate safety measures.

Some of the surrogate safety measures used for intersections are:

- Delay

- Travel time

- Approach speed

- Percent stop

- Queue length

- Deceleration distribution

- Traffic conflicts

The last measure is the most relevant for this research. The traffic conflict technique is a method with a long history of development and it has been used for several agencies as an operational tool. It has been proposed as a good indicator to measure of potential crashes without waiting for them to occur. 


\subsection{Traffic Conflict Technique}

In simple words, a traffic conflict is defined as a traffic event where two vehicles interact with each other and one or both drivers swerve or maneuver to avoid a collision (Glauz \& Migletz, 1980).

The traffic conflict technique was first mentioned in 1967 by two researchers from the General Motors Research Laboratories where they developed specific procedures on how to observe conflicts at intersections. The results proved that this technique identified conflict patterns for their corresponding crash pattern. Thus, traffic conflicts were considered to be a measured of potential crashes (Parker Jr \& Zeeger, 1989). However, along the way some issues with this technique were encountered, one of them being how to define the severity of the traffic conflict.

Hydén (1987), developed a measurement to define this severity: time-to-collision (TTC). The time interval would reflect a serious conflict, i.e., a near-crash, if the TTC threshold was below 1.5 seconds (Hydén, 1987). The traffic observers would later apply this to identify the category that each conflict belonged to. Based on this measurement and the speed of the driver performing the evasive action, Hydén displayed the interaction between road users as a safety pyramid (Figure 1) where the top represents an unavoidable collision (Hydén, 1987; Svensson, 1998).

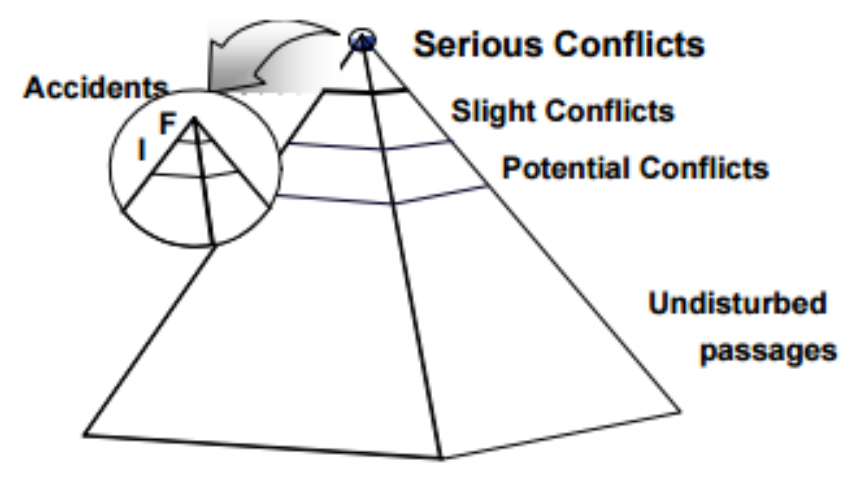

Figure 1: The safety pyramid (Hydén, 1987; Svensson, 1998)

The collection of possible conflicts at intersections was done by traffic conflict observers. By following a step-by-step instruction manual, these experts were able to conduct a survey in the 
field identifying and interpreting conflict data. These surveys would usually take from several hours to several days of manually recording traffic conflicts. Sometimes, to improve accuracy, the use of video equipment was implemented. Nowadays, there is another technique that combines microsimulation and conflict analysis in order to analyze and assess the safety of traffic facilities.

SSAM (Surrogate Safety Assessment Model), takes outputs from facilities already modeled in a compatible microsimulation software, such as VISSIM, Aimsun and Paramics, and analyzes vehicle-to-vehicle interactions identifying and categorizing all possible conflicts (FHWA, 2008).

SSAM uses various safety indicators such as time-to-collision, post-encroachment time, deceleration rate, among many others. These indicators are fully explained in section 2.5.3.

\subsection{Crash Modification Factors}

Crash modification factors (CMFs) are multiplicative factors that estimate expected crashes after a countermeasure has been implemented at a specific site (Gross, Persaud, \& Lyon, 2010). The purpose of CMFs is to serve as a tool regarding safety effects of a countermeasure. Examples of countermeasures include installing a traffic light, changing the width of edge lines and adding a barrier.

CMFs with a value greater than 1 indicate that the expected number of crashes, after applying countermeasure, will increase. On the other hand, a CMF below 1 indicates a decrease in the expected number of crashes.

For example, if the crash modification factor calculated when a traffic light is installed on a stopcontrolled intersection is 0.80 , based on the previous information, it can be seen that the CMF is less than one, which represents a crash reduction. This potential reduction will be of $20 \%$ (100*(1$0.8)$ ).

\subsection{Intelligent Transportation Systems}

Also known as ITS, intelligent transportation systems are defined by the ITS Canada as "advanced and emerging technologies in transportation to save lives, time, money, energy and the environment." (ITS Canada, 2012). The application of such technologies will help reduce traffic congestion, improve mobility and potentially increase safety on the roads. By using wireless data 
exchange from vehicle-to-vehicle (V2V) and vehicle-to-infrastructure (V2I), ITS allows communication within the transportation system avoiding unexpected movements from any surrounding road users. An example of this technology is connected and automated vehicles.

\subsubsection{Automated Vehicles}

Automated vehicles are those that do not require direct driver input to control certain operations such as steering, acceleration and braking (NHTSA, 2013). Furthermore, the automation involved in these vehicles is not always the same; the National Highway Traffic Safety Administration has defined the various levels of automation as follows:

- Level 0- No Automation: there is no presence of automation at this level, which allows the driver to have complete and sole control of the vehicle and its system (braking, steering, etc.) at all times. Vehicles can have driver support systems that only provide warnings and secondary system controls such as blind spot monitoring, turning signals, wipers, etc. (NHTSA, 2013).

- Level 1: Function-specific Automation: This level involves one or more controls specific to certain functions such as cruise control, lane keeping and automatic braking. The system may assist the driver with basic vehicle operations (steering or braking) but these cannot be combined. The driver has full control of the vehicle, but could allow the system to gain limited access over a primary control. (NHTSA, 2013)

- Level 2: Combined Function Automation: Automation at this level involves at least 2 primary control functions that can work in combination. At this point, the driver is temporarily relieved from the combined driving functions such as steering and speed control (NHTSA, 2013)

- Level 3: Limited Self-Driving Automation: The driver with a level 3 automated vehicle can now cede full control of operational functions to the system (braking, steering, etc.). At this level, the vehicle will monitor any changes in the road or surroundings that would require giving back full control to the driver (NHTSA, 2013).

- Level 4: Full Self-Driving Automation: The design of vehicles at this level allows them to operate all critical functions. At a level 4, the system will know that the driver is not 
expected to regain control or to operate the vehicle. Even if there is no driver in the vehicle, the system can fully operate and perform all functions (NHTSA, 2013).

It is important to take into consideration that these levels of automation, defined by NHTSA, are related to the ones established by the Society of Automotive Engineers (SAE), differing only by one level. NHTSA combines levels 4 and 5 from SAE into only level 4 (Ticoll, 2015).

For the purpose of this exploratory research, only one level of automation will be used during the simulation performed. Further explanation is given in section 3.1.1.2.

\subsubsection{Safety and Driving Behaviour of Automated Vehicles}

Human error is one of the main factors associated with vehicle crashes. This statement has been the conclusion of many studies involving road safety analysis. In 1979, the most extensive analysis on this topic was the Tri-Level Study of the Causes of Traffic Accidents. After investigating 2258 road accidents, it was found that human errors were accountable for $93 \%$ of probable cause of crashes (Treat, et al., 1979). The direct actions that caused the crashes were established as improper lookout and evasive action, excessive speed and inattention (Treat, et al., 1979).

A more recent study published in 2004 by Ray Fuller argues that driving behaviour cannot simply be the cause of crashes. Instead, it should be based on the concept of the difficulty of a task given to the driver and the task demand. If a driver is given too many tasks at the same time, and at different difficulty levels, a crash could then occur (Fuller, 2004).

Despite different theories and perspectives, everything leads to the fact that when drivers are not paying full attention to the road or cannot manage all tasks required by a motor vehicle; a crash is very likely to happen.

Table 1 highlights the top 8 causative factors for commercial vehicle crashes in Canada and how it categorizes the type of error for each action. The information presented in Table 1 shows that decision errors (D) are the primary cause for possible crashes. By introducing automated vehicles, many of these errors could be avoided. 
Table 1: Top 8 Causative Factors for Commercial Vehicle Crashes in Canada (Thiffault, 2011)

\begin{tabular}{|l|l|l|l|l|l|}
\hline \multicolumn{7}{|c|}{ Top causative factors } \\
\hline \multicolumn{7}{|c|}{ Commercial vehicles } & \multicolumn{3}{c|}{ Light vehicles } \\
\hline Factor & Estimate & Type & Factor & Estimate & Type \\
\hline Following to closely & 834 & $\mathrm{D}$ & Illegal maneuver & 244 & $\mathrm{D}$ \\
\hline Illegal manoeuvre & 227 & $\mathrm{D}$ & Fatigue & 163 & $\mathrm{NP}$ \\
\hline Inadequate surveillance & 220 & $\mathrm{R}$ & Illness & 129 & $\mathrm{NP}$ \\
\hline Too fast for conditions & 101 & $\mathrm{D}$ & Inattention & 92 & $\mathrm{R}$ \\
\hline Inattention & 78 & $\mathrm{R}$ & Internal distraction & 74 & $\mathrm{R}$ \\
\hline Stop required & 74 & $\mathrm{D}$ & Inadequate surveillance & 73 & $\mathrm{R}$ \\
\hline External distraction & 62 & $\mathrm{R}$ & Illegal drugs & 72 & $\mathrm{NP}$ \\
\hline Brake problems & 54 & $\mathrm{~V}$ & Too fast for conditions & 48 & $\mathrm{D}$ \\
\hline
\end{tabular}

$R=$ recognition, $D=$ decision, $V=$ vehicle, $N P=$ non-performance

AVs are characterized for their predictability in driving behaviour. Operational elements of such vehicles are pre-set and even though there could be a margin of error, their actions can be easily predicted in comparison to human driving responses. The way each person behaves behind the steering wheel is different because many habits and responses to certain situations are empirically learned. A study on collision detection in autonomous driving compares how known behaviours can be classified as safe (Figure 2 (Althoff, Stursberg, \& Buss, 2009)). By illustrating two vehicles passing each other on a straight road, it is possible to see in Figure 2(a) that trajectory and decision making of either vehicle is unknown, classifying this scenario as unsafe.

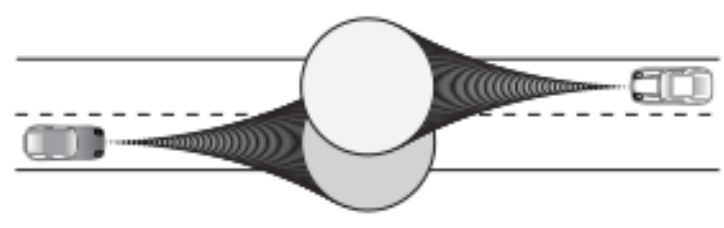

(a) Unknown Behaviour

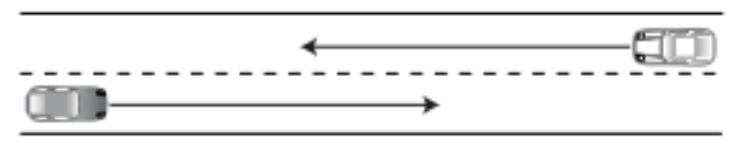

(b) Known Behaviour

Figure 2: Predictability of Driver Behaviour (Althoff, Stursberg, \& Buss, 2009)

This supports the idea that automated vehicles will have a predictable behaviour, which could be reflected in a decrease in potential crashes.

\subsection{Software Overview}

For the purpose of this research study, three software packages were used: SYNCHRO, VISSIM and SSAM. A short overview of each software package is presented below. 


\subsubsection{Synchro}

Synchro is a software package used for macroscopic analysis and optimization of signalized and unsignalized intersections as well as roundabouts (Trafficware, 2016). Synchro is based on the Highway Capacity Manual (HCM), which serves as a guide for proper application and evaluation of traffic operations, which is essential for microsimulation analysis.

In this study, Synchro was used to model the signalized intersections by using traffic volumes and signal timings provided. In addition, the optimization tool in Synchro was utilized in applying safety treatments to selected intersections which are discussed in Chapter 8.

\subsubsection{VISSIM Simulation Software}

The VISSIM software package can analyze private and public transport operations by using different parameters such as lane configuration, vehicle composition and public transit stops among many others (PTV, 2011). These features make VISSIM a great tool for evaluating future transportation and planning alternatives.

The traffic flow model on VISSIM is based on the car-following model process developed by Wiedemann and Reiter, which contains various parameters that could be altered to produce a more accurate simulated network.

There are two car-following models in VISSIM that are based on perception thresholds: Wiedemann 74 and Wiedemann 99. Figures 3 and 4 present the parameters included for each car following model. 


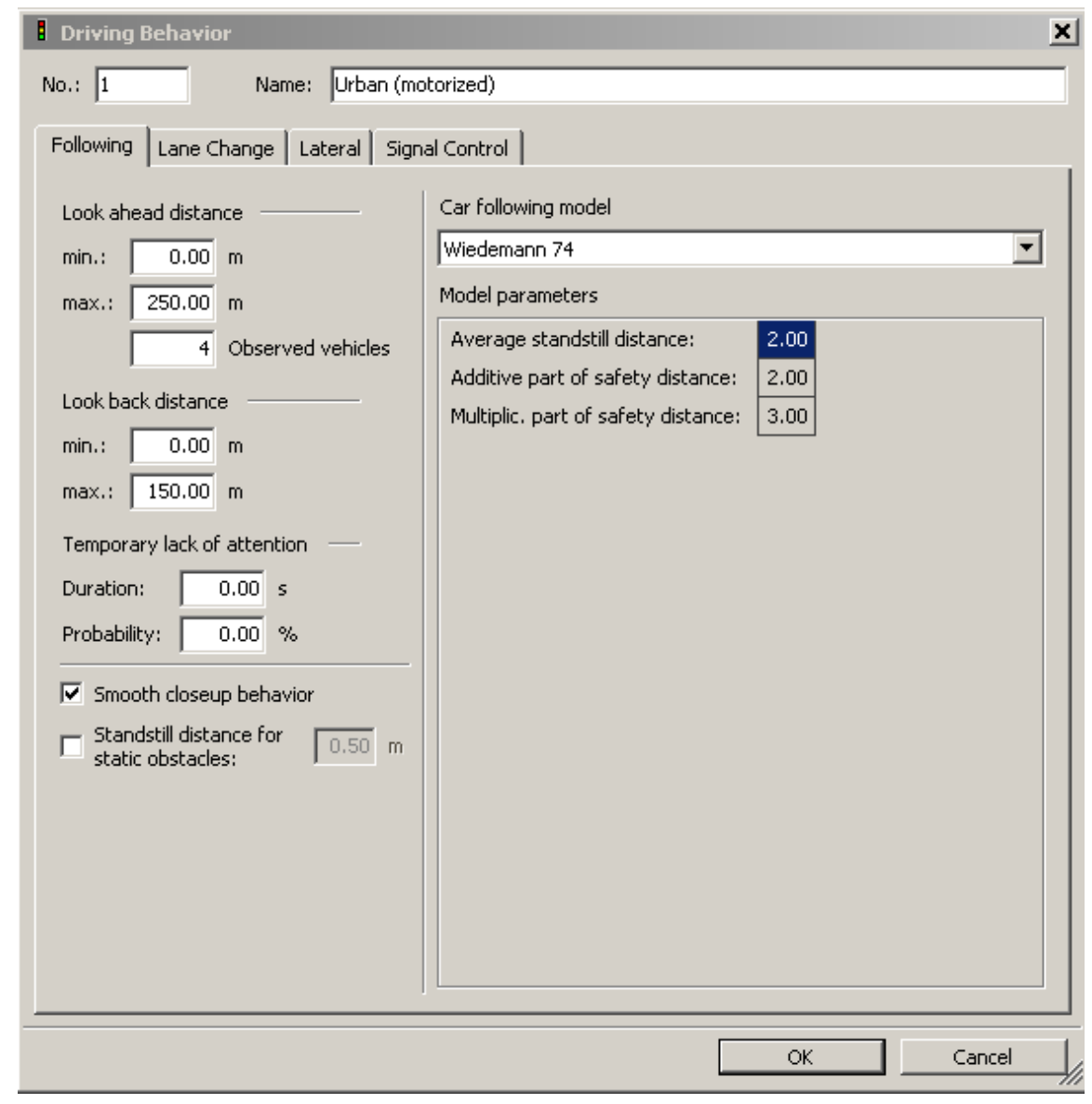

Figure 3: Driving Behaviour - Wiedemann 74 (PTV, 2011) 


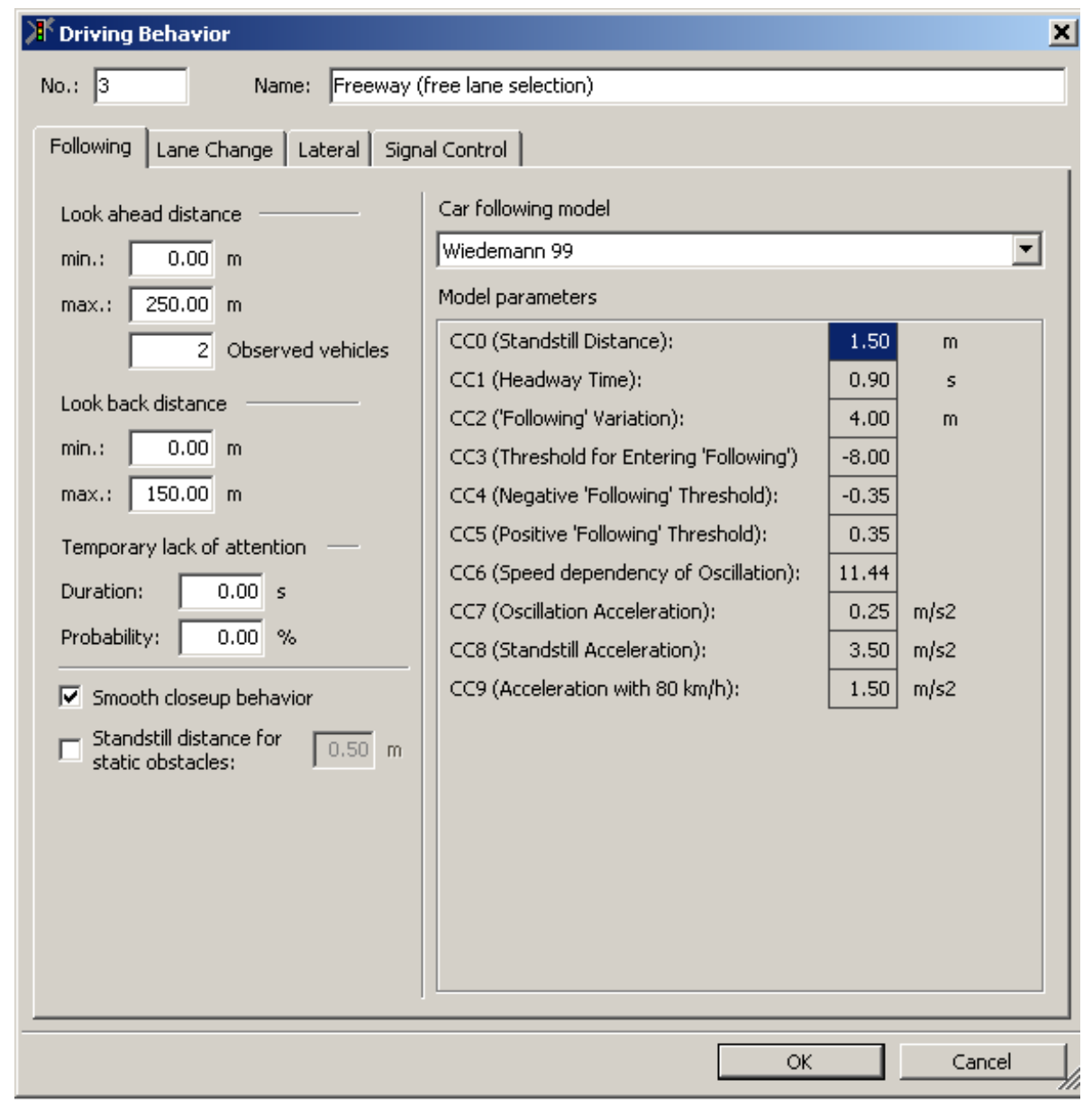

Figure 4: Driving Behaviour - Wiedemann 99 (PTV, 2011)

Even though these driving behaviours have some parameters in common, they are calculated differently. It is also important to mention that even though the Wiedemann 99 model is not specifically for urban settings, such as signalized intersections, it does have more parameters that can be changed. This diversity allows a more accurate representation of the driving behaviour of automated vehicles. More information about these changes are presented in Table 2. 
Table 2:Wiedemann 99 Model Parameters (PTV, 2011)

\begin{tabular}{|c|c|}
\hline MODEL PARAMETERS & DESCRIPTION \\
\hline CC0 (Standstill Distance) & $\begin{array}{l}\text { Defines the desired distance between stopped cars. } \\
\text { It has no variation. }\end{array}$ \\
\hline CC1 (Headway Time) & $\begin{array}{l}\text { Time (in seconds) that a driver wants to keep. The } \\
\text { higher the value, the more cautious the driver is. }\end{array}$ \\
\hline CC2 ('Following' Variation) & $\begin{array}{l}\text { Restricts the longitudinal oscillation or how much } \\
\text { more distance than the desired safety distance a } \\
\text { driver allows before he intentionally moves closer } \\
\text { to the car in front. The default value is } 4.0 \mathrm{~m} \text {. }\end{array}$ \\
\hline CC3 (Threshold for Entering 'Following') & $\begin{array}{l}\text { Controls the start of the deceleration process, i.e. } \\
\text { when a driver recognizes a preceding slower } \\
\text { vehicle. In other words, it defines how many } \\
\text { seconds before reaching the safety distance the } \\
\text { driver starts to decelerate. }\end{array}$ \\
\hline CC4 and CC5 ('Following' Thresholds) & $\begin{array}{l}\text { Control the speed differences during the } \\
\text { 'Following' state. Smaller values result in a more } \\
\text { sensitive reaction of drivers to accelerations or } \\
\text { decelerations of the preceding car, i.e. the vehicles } \\
\text { are more tightly coupled. CC4 is used for negative } \\
\text { and CC5 for positive speed differences. }\end{array}$ \\
\hline CC6 (Speed Dependency of Oscillation) & $\begin{array}{l}\text { Influence of distance on speed oscillation while in } \\
\text { following process. If set to } 0 \text { the speed oscillation } \\
\text { is independent of the distance to the preceding } \\
\text { vehicle. }\end{array}$ \\
\hline CC7 (Oscillation Acceleration) & Actual acceleration during the oscillation process. \\
\hline CC8 (Standstill Acceleration) & Desired acceleration when starting from standstill. \\
\hline CC9 (Acceleration at $80 \mathrm{~km} / \mathrm{h})$ & Desired acceleration at $80 \mathrm{~km} / \mathrm{h}$. \\
\hline
\end{tabular}

\subsubsection{Surrogate Safety Assessment Model (SSAM)}

The Surrogate Safety Assessment Model (SSAM) is a software package developed by the Federal Highway Administration Research and Technology as a tool to assess safety of traffic facilities. 
The software combines the output from microsimulation and conflict analysis based on vehicleto-vehicle collisions (Gettman, Pu, Sayed, \& Shelby, 2008). By applying various filters to the microsimulation outputs (trajectories), it is possible to define conflicts and their type. Table 3 identifies surrogate safety conflict measures used in SSAM.

Table 3: Description of Surrogate Conflict Measures (Gettman, Pu, Sayed, \& Shelby, 2008)

\begin{tabular}{|c|c|}
\hline Surrogate Conflict Measure & Description \\
\hline Time-to-collision (TTC) & $\begin{array}{l}\text { Minimum time-to-collision value observed during } \\
\text { the conflict. This estimate is based on the current } \\
\text { location, speed and trajectory of two vehicles at a } \\
\text { given instant. A value of zero indicates and actual } \\
\text { collision. }\end{array}$ \\
\hline Post-encroachment time (PET) & $\begin{array}{l}\text { Minimum post encroachment time observed during } \\
\text { the conflict. PET is the time between when the first } \\
\text { vehicle last occupied a position and the second } \\
\text { vehicle subsequently arrived to the same position. } \\
\text { A value of zero indicates and actual collision. }\end{array}$ \\
\hline Maximum Speed (MaxS) & $\begin{array}{l}\text { Maximum speed of either vehicle throughout the } \\
\text { conflict. }\end{array}$ \\
\hline Difference in Speeds (DeltaS) & $\begin{array}{l}\text { Difference in vehicle speeds as observed at } \\
\text { minimum TTC. }\end{array}$ \\
\hline Deceleration Rate (DR) & $\begin{array}{l}\text { Initial deceleration rate of the second vehicle. If the } \\
\text { vehicle brakes this is the first negative acceleration } \\
\text { value observed during the conflict. If the vehicle } \\
\text { does not brake, this is the lowest acceleration value } \\
\text { observed during the conflict. }\end{array}$ \\
\hline Maximum Deceleration (MaxD) & $\begin{array}{l}\text { Maximum deceleration of the second vehicle. A } \\
\text { negative value indicates deceleration (braking or } \\
\text { release of gas pedal). A positive value indicates } \\
\text { that the vehicle did not decelerate during the } \\
\text { conflict. }\end{array}$ \\
\hline $\begin{array}{l}\text { Maximum Difference in Conflict Velocity } \\
\text { (MaxDeltaV) }\end{array}$ & $\begin{array}{l}\text { Change between conflict velocity and the post- } \\
\text { collision velocity. This is a surrogate for the } \\
\text { severity of the conflict, calculated assuming a } \\
\text { hypothetical collision of the two vehicles in the } \\
\text { conflict. }\end{array}$ \\
\hline
\end{tabular}


The four types that conflicts are classified into are based on the absolute value of the conflict angle at which they occur. Rear end conflicts have an angle of less than 30 degrees, while lane change conflicts occur at an angle between 30 degrees and 85 degrees. Finally, crossing conflicts have an angle greater than 85 degrees (Gettman, Pu, Sayed, \& Shelby, 2008). Figure 5 depicts the angle and conflict classification used in SSAM.

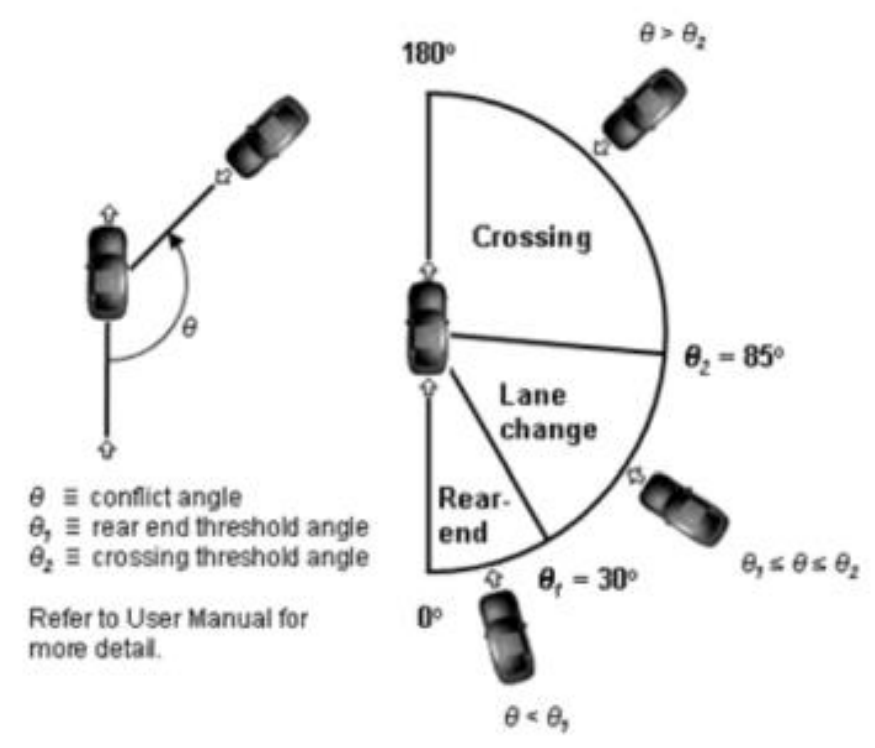

Figure 5: Angle Classification Diagram used in SSAM 


\section{Methodology}

This chapter describes the tools and key methodologies that were utilized to perform the microsimulation of the 78 4-legged signalized intersections, as well as the conflict analysis using the microsimulation output at three different penetration levels of automated vehicles. Additionally, it explains the application of crash prediction models and the calculation of crash modification factors $(\mathrm{CMF})$. Finally, it focuses on the evaluation of the effects of applying safety treatments to selected intersections.

\subsection{Microsimulation using VISSIM}

The 78 signalized intersections from the city of Toronto were first modelled in SYNCHRO. Signal timings and traffic volumes were used to create each intersection separately. The modelled intersections were then individually saved as a .csv file (comma delimited) which makes them compatible with VISSIM. These files were obtained from data used by Saleem (2012).

The .csv files for each intersection were then imported to VISSIM. The version of VISSIM used in this study was VISSIM 8.0. After importing the files, the outputs were chosen to be in a compatible file format with SSAM. Followed by this, 10 random runs for 3600 seconds (representing peak hour) were simulated for each intersection. Depending on the visualization used during the runs, VISSIM simulation took approximately 15 minutes per intersection. It is also important to consider that 20 random runs for 3600 seconds were also simulated for 25 intersections. However, there was no difference in results when changing this parameter.

The steps previously mentioned are applicable to all penetration levels of automated vehicles, but the initial one was specifically for $0 \%$ automated vehicles $(0 \% \mathrm{AV})$. However, before running the simulations with $50 \% \mathrm{AV}$ and $100 \% \mathrm{AV}$, some modifications had to be done to each modeled intersection to be able to reproduce an accurate simulation involving AVs.

\subsection{1 $100 \%$ AVs}

All the steps performed to simulate $100 \%$ automated vehicles in each intersection are described below.

First, the compatible Synchro file (.csv) was imported to a new file in VISSIM. Then, new vehicle types (AV cars and AV trucks) were created. 


\subsubsection{New vehicle type}

The Synchro files contained volumes for cars, trucks and pedestrians. Before creating a new vehicle type, a 2D/3D model distribution involving each future vehicle type was created. To be consistent, six types of cars (Peugeot 607, Audi A4, Mercedes CLK, Porsche Cayman, Toyota Yaris and Volkswagen Beetle) were added to the 'AV Car' vehicle type and only one type of truck was added to the 'AV Truck' vehicle type. The type of truck used was a single-unit truck with two axles. The main reason for doing this is to have a variety of vehicles that simulate reality in a more accurate way.

It is important to note that the desired speed distribution did not change for automated vehicles due to the lack of research on this area. It was assumed that the total number of vehicles on the road that were $100 \%$ automated would uniformly move without going over the speed limit. Based on a recent webinar hosted by PTV Group (VISSIM developers) about simulation of AVs, it is expected that the speed distribution for AVs will be uniform when compared to non-automated vehicles, since they will be able to drive at a constant speed through the intersection. This statement was based on values obtained for average delay and queue length during a performed live simulation.

Once these new parameters were created, the addition of the new vehicle types was possible. Finally, a new vehicle type must be given a vehicle class that will later be used to designate volumes belonging to a specific class. For this reason, two new vehicle classes were added to the VISSIM library.

\subsubsection{Driving Behaviour}

As previously mentioned, to replicate as close as possible how automated vehicles would behave

on the roads, a new driving behaviour was created. To do so, the Wiedemann 99 car-following model was chosen. As noted earlier, even though this driving behaviour is primarily used to represent vehicle behaviour in freeways, it allows the user to change many more parameters in comparison to Wiedemann 74 to be able to better represent automated vehicles.

The new values for each parameter were based on previous research done by (Bierstedt, et al., 2014) about aggressive driving behaviour on vehicles with adaptive cruise control (ACC). 
Nevertheless, it is important to understand that these values simulate performance of individual vehicle technologies that are capable of sensing what is happening several vehicles ahead and alongside. However, it does represent connectivity among all vehicles on the road (Bierstedt, et al., 2014).

To create a more accurate driving behaviour representing AVs, results of another research study that specifically addressed AVs were used. This research from Sweden studied the effects of automated vehicles on traffic performance (Aria, 2016).

Figures 6 and 7 show the new values for each parameter of the driving behaviour altered in VISSIM for the car-following and lane change.

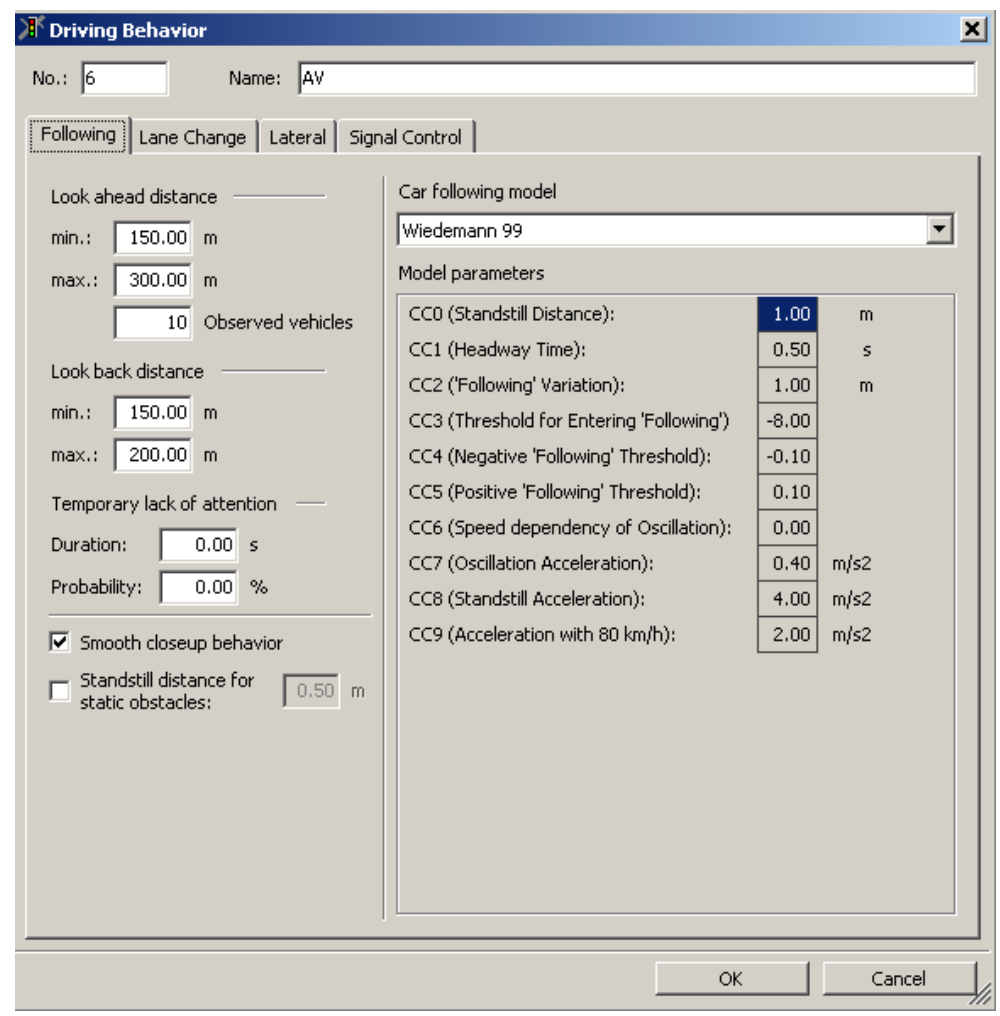

Figure 6: Driving Behaviour for AVs (Car-following) 


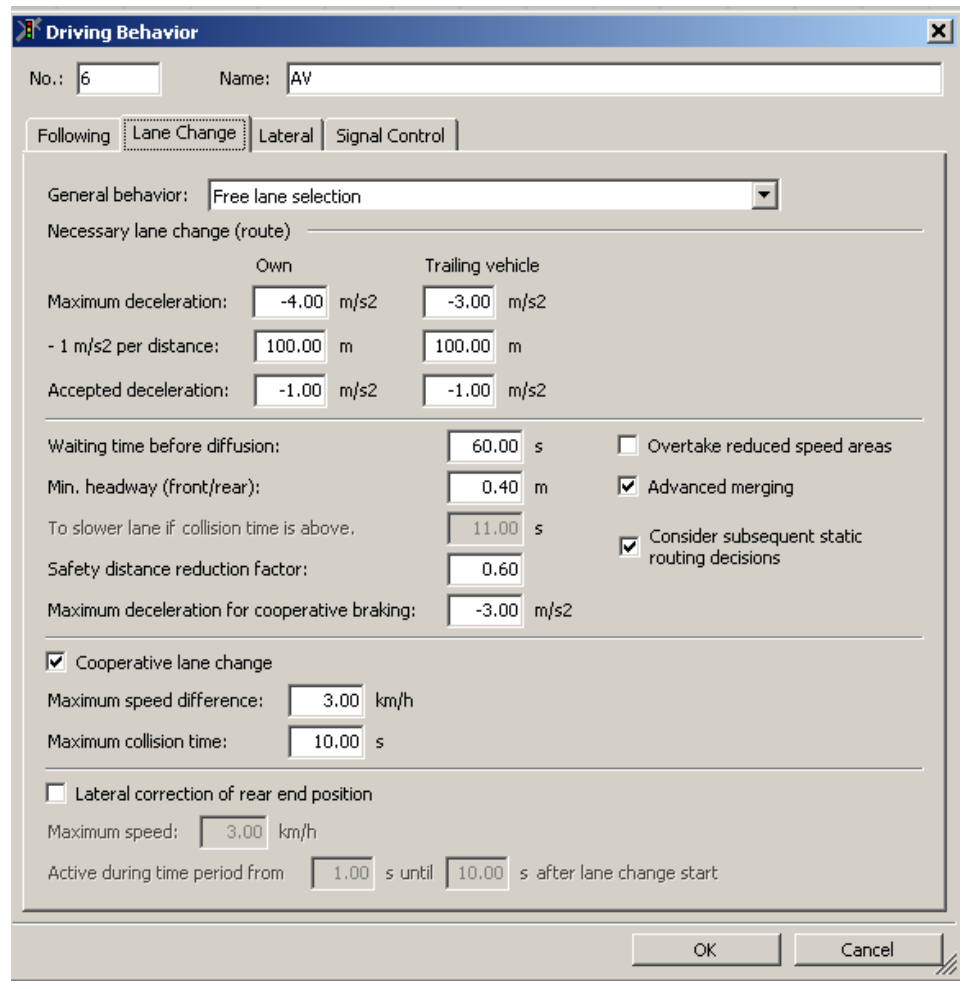

Figure 7: Driving Behaviour for AVs (Lane Change)

As mentioned in Section 1.3, all automated vehicles are assumed to have the same level of automation (Level 3). The main reason for this assumption is that most of the published research on AVs is based on this specific level (i.e. driving behaviour parameters of AVs, driving behaviour of non-automated vehicles when mixed with AVs and decision time for AVs when making a left turn).

An example of these works is a study by TRL Limited (2017) on the integration of AVs and nonautomated vehicles when crossing a junction. Another example pertains to the action of regaining control from an automated vehicle (Merat, Jamson, Lai, Daly, \& Carsten, 2013).

Based on this assumption of having all AVs as level 3, the values of the parameters for the driving behaviour were changed. Below is the explanation of these changes.

- Minimum look ahead/back distance: least visible distance that a driver can react appropriately. For level 3 AVs, the vehicle's sensors will control this parameter.

- Number of observed vehicles: this value ranges from 6 to 8. Following (Bierstedt, et al., 2014), a value of 10 was given. However, when a value of 7 was used to run a simulation, there was no change on the number of conflicts generated. 
- Headway: a time of 0.5 seconds was used for this study, keeping the vehicles closer to each other but without affecting safety.

- Cooperative Lane Change: automated vehicles of this level will be able to communicate with each other and let the other drivers know when maneuvers will be made. Hence, the activation of this feature.

- Advance Merging: adequate and safe lane changes characterized AVs. By knowing ahead of time the desired route, earlier lane changes will happen during the driving path. Thus, advance merging was activated.

- Consider subsequent static route decisions: vehicle will identify new routing decisions in advance and will choose a lane based on it (PTV, 2011). Automated vehicles will plan their routes in advance and will make necessary lane changes ahead of time.

\subsubsection{New Volumes}

After defining the driving behaviour for AVs, the volume inputs originally added in Synchro, had to be matched to the new vehicle types created earlier. This change was applied to 'Vehicle Compositions' and 'Static Vehicle Routing Decisions'.

Vehicle compositions consist of a list of all vehicle types that are to be simulated on the roads. Each of these vehicle types is assigned a flow percentage and a speed distribution (PTV, 2011). However, when importing the modeled network from Synchro, vehicle composition represented the total volumes that originated at each start point. Figure 8 illustrates this list of volumes:

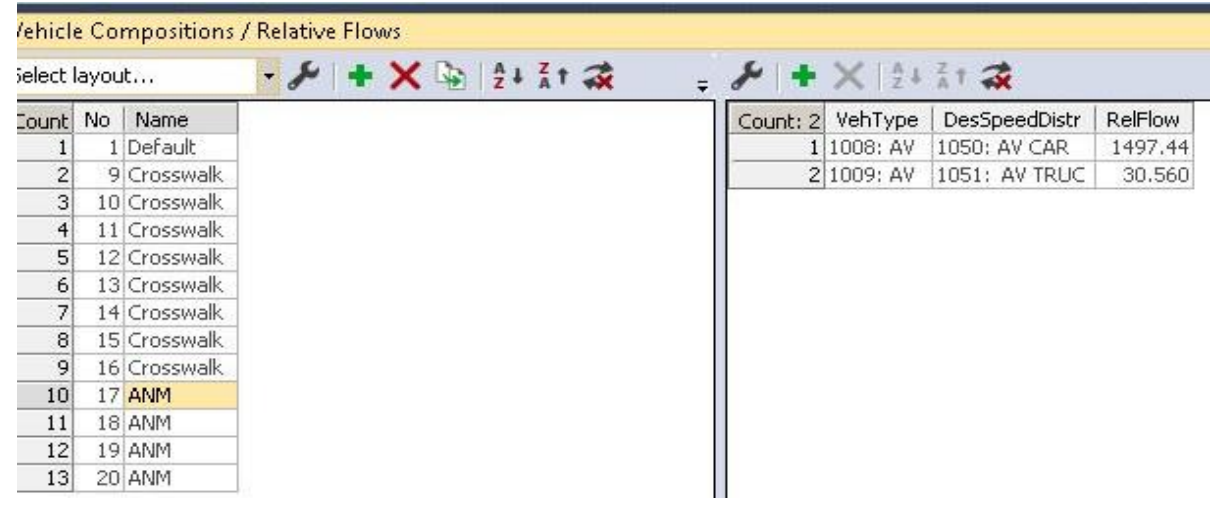

Figure 8: Vehicle Composition for 100\% Penetration Level of AVs

The second change in volumes was applied to 'Static Vehicle Routing Decisions'. These routes define the path that vehicles are allowed to take (through, left and/or right movements). Static 
routes limit the percentage of vehicles that go from a start point to a destination point. Since only 4-legged signalized intersections were used in this study, a maximum of three static routes were possible. Figure 9 depicts the three possible routes coming from a southbound leg:

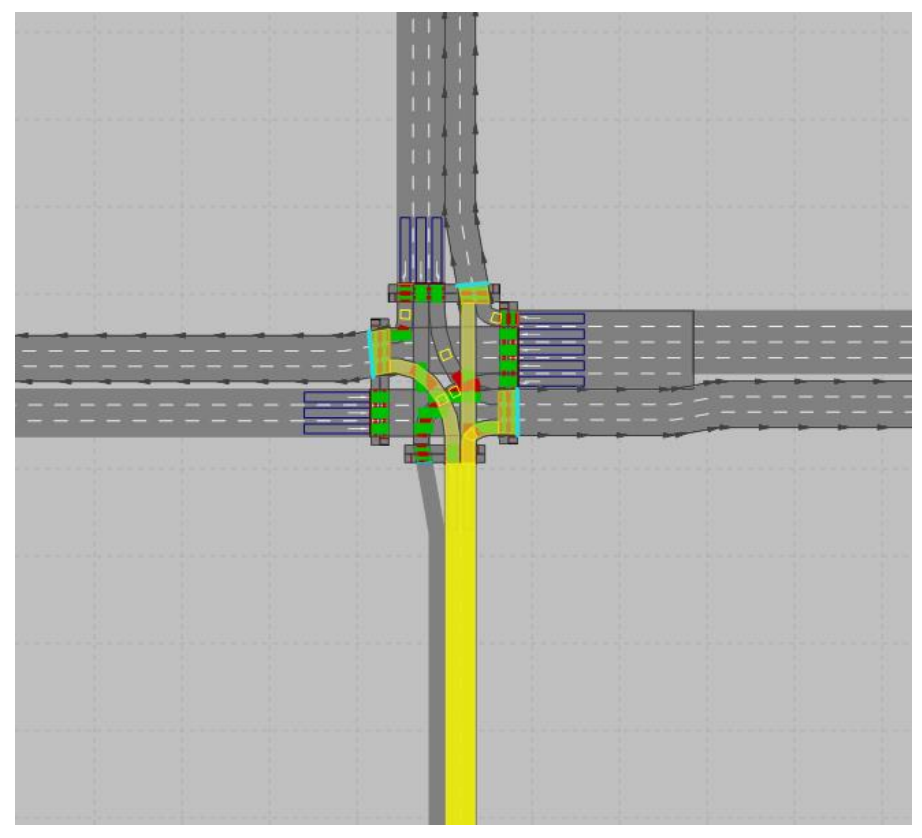

Figure 9: Sample of Vehicle Routes in VISSIM

Similar to 'Vehicle Compositions', these static routes have to be matched to a vehicle type. Therefore, the software will know how many automated vehicles are coming from a westbound leg and whether they are turning right or left. This process is repeated with all the possible routes the vehicles can take and their respective volume.

For the simulation of $100 \% \mathrm{AVs}$, there was no change in volumes. The only changes required were those that inform the software that there is now a new vehicle with different characteristics. The distribution of the volumes was changed for the $50 \%$ AV scenario. Explanation of this is approach is given in the following section.

\subsubsection{0\% AVs}

With a new driving behaviour for $\mathrm{AVs}$, different penetration levels were modeled. For the 50\% AV scenario, all the steps previously mentioned were repeated (Section 3.1.1). However, the volumes now had to be divided in half to account for automated and non-automated vehicles. It is 
important to note that all trucks were kept fully automated during this scenario. Only the volume distribution of cars was altered.

A new vehicle type was added to the 'Vehicle Compositions' section. This new vehicle type was the already existing non-automated vehicle type used for $0 \% \mathrm{AV}$ penetration level. The volumes were then divided in half for each vehicle type.

Similarly, a non-automated vehicle class (denoted as VehClass: 70) was added to the static vehicle routes section. The distribution of volumes regarding this class 70 was half of the original volume of fully automated cars used for the $100 \%$ penetration level.

Figures 10 and 11 show the addition of the non-automated cars to the simulation (Vehicle type: 100 and Vehicle class: 70).

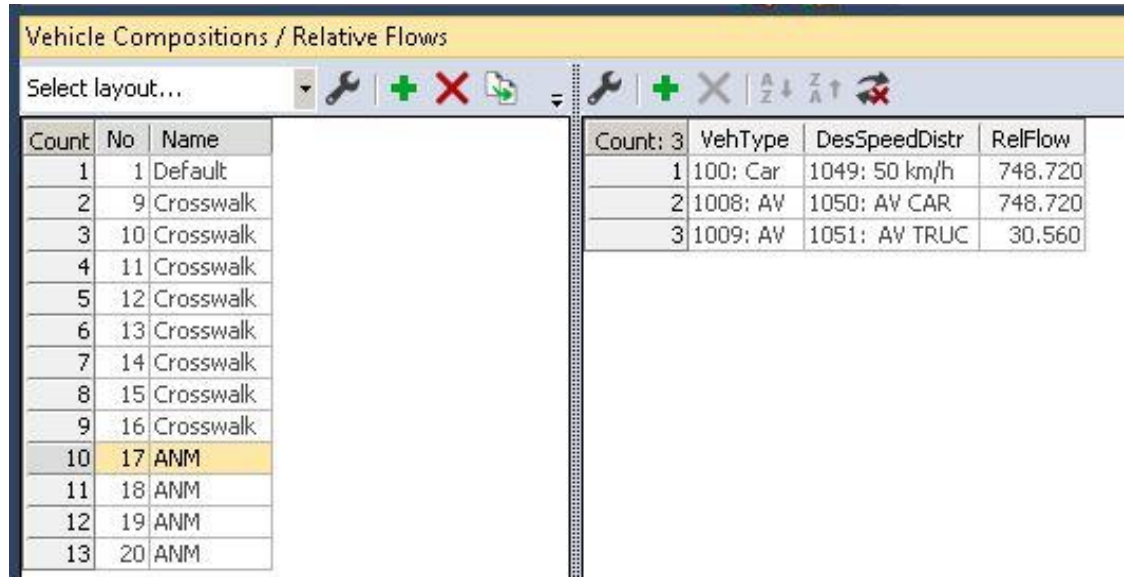

Figure 10: Vehicle Composition for 50\%AVs 


\begin{tabular}{|c|c|c|c|c|c|c|c|}
\hline \multicolumn{8}{|c|}{ Static Vehicle Routing Decisions / Static Vehicle Routes } \\
\hline \multicolumn{3}{|c|}{ Select layout... } & \multirow{2}{*}{$\frac{-\infty}{\text { Link }}$} & \multirow{2}{*}{ 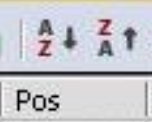 } & \multirow{2}{*}{$\frac{* \text { Static ve }}{\text { Allwehtypes }}$} & \multirow[b]{2}{*}{ VehClasses } & \multirow[t]{2}{*}{ - E⿹ } \\
\hline Count & No & Name & & & & & \\
\hline 1 & 1 & ANM node 3 & 3: Dufferin St & 0.031 & $\square$ & 90 & \\
\hline 2 & 2 & ANM node 3 & 3: Dufferin St & 0.031 & $\square$ & 100 & \\
\hline 3 & 3 & ANMM node 3 & 4: Dufferin St & 0.031 & $\square$ & 90 & \\
\hline 4 & 4 & ANM node 3 & 4: Dufferin St & 0.031 & $\square$ & 100 & \\
\hline 5 & 5 & ANM node 3 & 5: Eglinton Ave & 0.031 & $\square$ & 90 & \\
\hline 6 & 6 & ANM node 3 & 5: Eglinton Ave & 0.031 & $\square$ & 100 & \\
\hline 7 & 7 & ANM node 3 & 6: Eglinton Ave & 0.031 & $\square$ & 90 & \\
\hline 8 & 8 & ANM node 3 & 6: Eglinton Ave & 0.031 & $\square$ & 100 & \\
\hline 9 & 9 & ANM node 3 & 6: Eglinton Ave & 0.031 & $\square$ & 70 & \\
\hline 10 & 10 & ANM node 3 & 5: Eglinton Ave & 0.031 & $\square$ & 70 & \\
\hline 11 & 11 & ANM node 3 & 4: Dufferin St & 0.031 & $\square$ & 70 & \\
\hline 12 & 12 & ANM node 3 & 3: Dufferin St & 0.031 & $\square$ & 70 & \\
\hline
\end{tabular}

Figure 11: Static Vehicle Routes for 50\%AV scenario

\subsection{Conflict Analysis using SSAM}

After the 10 simulations for each intersection were completed in VISSIM, their respective outputs were imported in SSAM. The analysis in SSAM resulted in possible conflicts generated at each intersection. As mentioned earlier, the results obtained from the SSAM analysis were filtered to remove any uncertainties, including possible conflicts of pedestrians. The filters used are explained in Table 3 (Section 2.5.3).

Per Saleem (2012), the principal reason for removing the pedestrian conflicts is that in his study, only vehicle-to-vehicle crashes were modeled. In the same way, this study only focuses on evaluating safety of signalized intersections with the presence of automated vehicles without including pedestrians due to the lack of research on the topic.

To be consistent, the filters used for each intersection were the same ones used by Saleem (2012). The $0 \% \mathrm{AV}$ scenario is based on his original data and simulation results. To be able to compare crashes later using the crash-conflict prediction models also developed by Saleem (2012), the ranges used for each conflict analysis had to be the same. The filters used varied from intersection to intersection, yet the filter applied to the intersection coordinates was the same (50 meters radius of the center of the intersection). This filter was applied because the crash data available for Saleem's study accounted for crashes within $50 \mathrm{~m}$ from the intersection. 


\subsection{Application of Crash Prediction Models}

Based on the different variables such as conflicts, AADT and peak hour ratio, Saleem developed various crash prediction models. Four of these models were applied to the conflicts obtained for the three penetration levels $(0 \% \mathrm{AV}, 50 \% \mathrm{AV}$ and $100 \%)$. These predicted crashes were later used to calculate the crash modification factor for each model.

\subsection{Crash Modification Factors}

As explained in Section 2.3, CMFs indicate the expected number of crashes after implementing a countermeasure. In this case, the countermeasure is the introduction of automated vehicle to each of the 78 signalized intersections. These crash modification factors were derived from the crashconflict models used.

The CMF was calculated for each crash prediction model applied in both scenarios: 50\% AV and $100 \%$ AV. Using the method studied by Shahdah, Saccomanno, \& Persaud (2014) to predict the CMF based on simulated conflicts, the total predicted crashes after the countermeasure was applied (crashes at $100 \% \mathrm{AV}$ and crashes at $50 \% \mathrm{AV}$ ) were divided by the total predicted crashes before the countermeasure was applied (crashes at $0 \% \mathrm{AV}$ ). This provided crash modification factors for the two AV penetration levels investigated in this study.

Finally, to have a better perspective with regards to simulated conflicts and crashes, an average was calculated for each element used to calculate the CMFs for the four prediction models (crashes at $0 \% \mathrm{AV}$, crashes at $100 \% \mathrm{AV}$, crashes at $50 \% \mathrm{AV})$. With these new values, new CMFs were calculated for $100 \% \mathrm{AV}$ and $50 \% \mathrm{AV}$ with respect to the untreated site scenario of $0 \% \mathrm{AV}$.

\subsection{Evaluation of Safety Treatments for Signalized Intersections}

After analyzing the safety of the 78 signalized intersections when introducing automated vehicles, this part of the research explored and evaluated the safety effects on crashes when hypothetical treatments were applied to selected intersections.

The first safety treatment consisted of changing the left turn operation from permissive to permissive-protected. Permissive left turns can raise safety concerns since drivers take a higher risk in crossing the intersection at a gap that is considered by the driver as acceptable (Stewart \& 
Al-Kaisy, 2001). By providing a permissive-protected left turn, the intersection protects many drivers from this risk since left turns are now unopposed to the rest of the intersection and can potentially handle greater volumes with less delays (Stewart \& Al-Kaisy, 2001). This change in phasing by itself can improve safety.

This treatment was introduced through the simulation for 13 of the 78 signalized intersections at each penetration level. The files were originally changed and optimized in Synchro and subsequently exported to VISSIM. The same steps mentioned in section 3.1 were applied in order to run the simulations for the three penetration levels of automated vehicles.

Next, the VISSIM outputs were analyzed in SSAM and filtered to obtain vehicle-to-vehicle conflicts per intersection. With these conflicts, the crashes for the 13 signalized intersections were then predicted using six models developed by Saleem (2012). In order to compare before and after results, the same six crash prediction models used in this section were applied to conflict data obtained in Section 3.2. Finally, the CMFs were estimated and compared to those before this safety treatment was applied. Additionally, the outcome for the CMFs at a $0 \% \mathrm{AV}$ penetration were compared to the results obtained in a study by Saleem (2012), which used similar intersections to apply the same safety treatment.

The second safety treatment applied was the addition of an exclusive left turn lane. Separate left turn lanes are known for safety by helping vehicles to decelerate and move away to their turning lane from the through traffic, which potentially helps to reduce queues (Hallmark \& Hawkins, 2014). Additionally, and based on studies presented in the report by Hallmark \& Hawkins (2014), the introduction of the exclusive left turn lane could help reduce crashes up to 70\% (Hallmark \& Hawkins, 2014). For this reason, 11 of the 78 signalized intersections were selected and following similar steps described for the first safety treatment, CMFs were estimated by comparing estimated crashes before-and-after its application. 


\section{Summary of Data and Crash Prediction Models Used}

This chapter will explain information about the data used and the study area considered for this research study. It is important to note that the data used in this research are the same used in a study by Taha Saleem about the "Evaluation of the Predictive Capabilities of Simulated Peak Hour Conflict Based Crash Prediction Models" (Saleem, 2012).

\subsection{Traffic Data}

The area used for this study is in the City of Toronto and includes the areas of downtown, East York, North York and Scarborough. Data for a group of 1786 4-legged signalized intersections were provided the Traffic Control Centre (Saleem, 2012). The data included signal timings and traffic volumes.

For this study, 78 of the 113 signalized intersections from Saleem's study were used. The data for the missing 35 intersections was unable to be recovered and for this reason, these intersections were not used in this study. Further explanation of the pertinent Saleem's study is provided in the following section.

\subsection{Information from Study by Saleem}

Research study by Saleem (2012) used simulated traffic of 114 4-legged signalized intersections to develop crash prediction models in order to be used to predict crashes for signalized intersections in the city of Toronto. These models were used for the current study; hence their development is summarized in following sub-sections.

\subsubsection{Simulation}

The intersections were first modeled by Saleem in Synchro software by using data volumes and signal timings provided. The data also included important aspects of road geometry and operational traffic such as number of lanes (including exclusive right or left turn lanes), lane widths, allowance of right turn on red (RTOR) and posted speed limit (Saleem, 2012). The intersections were then exported to VISSIM where the Wiedemann 74 car-following model, designed for urban settings and for right-side motorized rule, was used to simulate 10 random runs. Pre-set values from this driving behaviour were used. 


\subsubsection{Filtering Conflicts Using SSAM}

Outputs for each intersection (trajectories) were exported from VISSIM software to be analyzed in SSAM.

By using the surrogate conflict measures previously mentioned in Table 3, uncertainties were removed. For example, default minimum values for TTC and PET were given as zero by SSAM. However, a value of zero represents a crash and what is needed for this analysis is conflicts (nearcollisions); hence a minimum value of 0.1 seconds was used to only account for conflicts. Another filter was applied to remove pedestrian conflicts since SSAM does not differentiate pedestrians and vehicle conflicts. The filter used in this case was a speed no less than 5mph (Saleem, 2012). The conflicts obtained once filters were applied, were used to predict crashes using previously developed crash-conflict prediction models.

\subsubsection{Crash Prediction Models}

Different prediction models were developed to relate crash types to its respective conflict type. These models were developed using signalized intersections in the city of Toronto, including the ones used in this study. The general equation used was the following (Saleem, 2012):

crashes per year $=e^{\alpha} \times$ conflicts $^{\beta 1} \times$ peak hour ratio $^{\beta 2} \quad$ (Equation 1$)$

where $\alpha$ and $\beta$ are regression estimates previously calculated. Once these values were estimated, parameters for crash prediction models using conflicts were calculated. Table 4 summarizes these values. It is important to take into consideration that this model as well was regression estimates, are to be kept fixed since it will be used to predict crashes for $0 \% \mathrm{AV}$ and in the presence of automated vehicles. 
Table 4: Parameters for Crash Models Based on Simulated Traffic (Saleem, Persaud, Shalaby, \& Ariza, 2014)

\begin{tabular}{lllll}
\hline $\begin{array}{l}\text { Crash Type for } \\
\text { Dependent Variable }\end{array}$ & $\begin{array}{l}\text { Conflict Type for } \\
\text { Independent Variable }\end{array}$ & $\begin{array}{l}\alpha \text { Estimate } \\
\left(\operatorname{Pr}>\chi^{2}\right)\end{array}$ & $\begin{array}{l}\beta_{1} \text { Estimate } \\
\left(\operatorname{Pr}>\chi^{2}\right)\end{array}$ & $\begin{array}{l}\beta_{2} \text { Estimate } \\
\left(\operatorname{Pr}>\chi^{2}\right)\end{array}$ \\
\hline Total & Total & $-0.9722(.2771)$ & $0.3461(<.0001)$ & $-1.0775(.0023)$ \\
Total & Crossing & $1.062(.1047)$ & $0.2741(<.0001)$ & $-0.5788(.0730)$ \\
Total & Rear end & $-0.6492(.4536)$ & $0.3065(<.0001)$ & $-1.0334(.0035)$ \\
Total & Lane change & $1.0071(.1437)$ & $0.2450(.0003)$ & $-0.6489(.0520)$ \\
Injury & Total & $-1.7527(.0543)$ & $0.3030(<.0001)$ & $-0.8498(.0164)$ \\
Injury & Crossing & $-0.0934(.8837)$ & $0.3043(<.0001)$ & $-0.4059(.1939)$ \\
Injury & Rear end & $-1.4876(.0910)$ & $0.2720(.0001)$ & $-0.8117(.0217)$ \\
Injury & Lane change & $-0.263(.7012)$ & $0.2402(.0003)$ & $-0.5746(.0823)$ \\
PDO & Total & $-1.4144(.1346)$ & $0.3593(<.0001)$ & $-1.1303(.0025)$ \\
PDO & Crossing & $0.7333(.2928)$ & $0.2655(<.0001)$ & $-0.6148(.0742)$ \\
PDO & Rear end & $-1.0782(.2391)$ & $0.317(<.0001)$ & $-1.0871(.0038)$ \\
PDO & Lane change & $0.7129(.3288)$ & $0.2451(.0008)$ & $-0.6574(.0635)$ \\
Angle & Crossing & $-0.8015(.2791)$ & $0.2549(.0020)$ & $-0.7117(.0485)$ \\
Rear end & Rear end & $-1.2676(.2341)$ & $0.3423(<.0001)$ & $-0.6609(.1264)$ \\
Sideswipe & Lane change & $-1.6218(.1494)$ & $0.2608(.0159)$ & $-1.0133(.0639)$ \\
Turning & Crossing & $-0.7581(.3321)$ & $0.3158(.0009)$ & $-0.5477(.1643)$ \\
\hline
\end{tabular}

NOTE: $\mathrm{PDO}=$ property damage only; $\mathrm{Pr}=$ probability . 


\section{Simulation and Conflict Analysis}

In Chapter 3.1, it was mentioned that VISSIM outputs (trajectories) for each of the 78 signalized intersections were exported to SSAM. Once in this software, these trajectories were analyzed to represent possible conflicts. On the following sections, the results obtained for the number of possible conflicts will be illustrated and discussed.

\subsection{Penetration Level: 0\% AV}

The simulations for the 78 signalized intersections were run without major changes to the software parameters. A penetration level of $0 \% \mathrm{AV}$ represents exactly the situation that is currently happening on the roads. This simulation does assume that any vehicle that has some level of automation (V2V communications) can be neglected since is very likely that it will not be used at an urban signalized intersection (e.g. cruise control). After 10 simulation runs, the outputs were exported to SSAM. Ten trajectories were then analyzed by this software package and filtered, producing the results displayed in Table 5.

Table 5: Estimated Conflicts for Sites with $0 \% A V$

\begin{tabular}{|c|c|c|c|c|}
\hline Collisions & Mean & Minimum & Maximum & Percentage \\
\hline TOTAL & 1447.47 & 104 & 4480 & $100 \%$ \\
\hline CROSSING & 93.30 & 0 & 236 & $6.45 \%$ \\
\hline REAR END & 1271.49 & 53 & 4158 & $87.84 \%$ \\
\hline LANE & & 4 & 311 & $5.72 \%$ \\
\hline
\end{tabular}

The percentage of rear end conflicts represents the highest possible number of conflicts at all 78 sites. One of the primary reasons is due to the way SSAM classifies conflicts based on the angle of occurrence. Figure 5 depicts the conflict classification used by SSAM, which shows that any conflicts happening with an angle below $30^{\circ}$ fall under the rear end conflict type.

Based on a study that analyzes the methodology of conflicts used by SSAM, it was found that the software could over-estimate rear end crashes while under-estimating lane change conflicts due to the angle overlapping for these two conflict types. Rear end conflicts tend to happen at angle between $0^{\circ}$ to $44^{\circ}$, while lane change conflicts can range from $0^{\circ}$ up to $58^{\circ}$ (Souleyrette \& 
Hochstein, 2012). Even though it is known that rear end conflicts happen at small angles, a new threshold should be added so conflicts can be differentiated from a possible lane change conflict to an actual rear end conflict.

It is important to also notice that the minimum value obtained for crossing conflicts is zero. This is due to the fact that some of the analyzed intersections had prohibited left turns, creating no conflicts.

\subsection{Penetration Level: $50 \% \mathrm{AV}$}

As mentioned in Section 3.1.2, some changes in the driving behaviour had to be performed in the VISSIM software to represent the $50 \%$ automated vehicles on the road. After dividing the total traffic volume from $0 \% \mathrm{AV}$ to be fifty percent automated, 10 simulations were run. Similarly, to the previously described scenario, the VISSIM outputs were analyzed in SSAM giving the results summarized in Table 6.

Table 6: Estimated Conflicts for Sites with 50\%AV

\begin{tabular}{|c|c|c|c|c|}
\hline Collisions & Mean & Minimum & Maximum & Percentage \\
\hline TOTAL & 617.66 & 66 & 1849 & $100.00 \%$ \\
\hline CROSSING & 102.06 & 0 & 345 & $16.52 \%$ \\
\hline REAR END & 462.79 & 62 & 1463 & $74.93 \%$ \\
\hline $\begin{array}{c}\text { LANE } \\
\text { CHANGE }\end{array}$ & 52.81 & 4 & 162 & $8.55 \%$ \\
\hline
\end{tabular}

Once again, it can be observed that rear end conflicts lead the percentage of possible conflicts. However, when comparing these results to the ones obtained for the $0 \% \mathrm{AV}$ scenario, there is already a significant difference in total conflicts. At a 50\% penetration level of automated vehicles, a potential reduction in conflicts is perceived. The mean for total conflicts has decreased from 1448 to 618 possible conflicts. Even though this is not a measure of crash reduction, it is a sign of less dangerous interaction between the road users.

The percentages displayed in Table 6 attribute the majority of conflicts (highest mean) to total conflicts, so lane change, for example, represents almost $9 \%$ of those total conflicts. 


\subsection{Penetration Level: $100 \% \mathrm{AV}$}

Using the same new driving behaviour created to simulate 50\% AV penetration level, it was possible to simulate the $100 \% \mathrm{AV}$ scenario. In this case, there is no change of volume. Instead, the new vehicle types (AV Car and AV Truck) were matched to their respective volumes originally entered in the $0 \% \mathrm{AV}$ scenario. The VISSIM outputs of 10 simulations were exported to SSAM to be analyzed. After applying the filters to each intersection, the possible conflicts were obtained. These are shown in Table 7.

It can be seen that at $100 \% \mathrm{AV}$ the total conflicts decrease by more than $30 \%$ when compared to $0 \% \mathrm{AV}$ scenario. As expected, by having all vehicles on the road as a level 3 automation, maneuvers become more predictable, thereby reducing unexpected situations.

Likewise, a reduction in conflicts is seen from not having mixed traffic as in the 50\% AV scenario. Though, this reduction is not as substantial as the one observed when comparing $100 \% \mathrm{AV}$ and $0 \% \mathrm{AV}$.

Table 7: Estimated Conflicts for Sites with 100\%AV

\begin{tabular}{|c|c|c|c|c|}
\hline Collisions & Mean & Minimum & Maximum & Percentage \\
\hline TOTAL & 562.03 & 52 & 1970 & $100.00 \%$ \\
\hline CROSSING & 110.43 & 0 & 380 & $19.65 \%$ \\
\hline REAR END & 399.38 & 47 & 1729 & $71.06 \%$ \\
\hline LANE & 52.18 & 5 & 195 & $9.28 \%$ \\
CHANGE & & & & \\
\hline
\end{tabular}

Similar to Table 6, in Table 7 the percentages of conflicts obtained are shown. Here, it can be observed that in the presence of AVs the rear end conflicts diminish compared to the 50\% AV and $0 \%$ AV scenario. This could be attributed to specific driving behaviour parameters added to the automated vehicles. 


\section{Crash Prediction and Evaluation}

After having the possible number of conflicts at each intersection, the crashes were predicted by using the crash prediction models presented in Table 4. As noted earlier, these models were developed by Saleem (2012) for 4 leg urban signalized intersections in Toronto. The four models selected to calculate crashes were based on the following combinations:

- Total crashes from total conflicts

- Injury crashes from total conflicts

- Angle crashes from crossing conflicts

- Rear end crashes from rear end conflicts

By using $\boldsymbol{\alpha}, \boldsymbol{\beta}_{1}$ and $\boldsymbol{\beta}_{2}$ estimates from Table 4 and the peak hour ratio for each intersection, the number of crashes (per type) were predicted by using the respective number of conflicts. The first model applied, predicted the total number of crashes per year by using total conflicts. The second model predicted the total injury crashes per year by using the total number of conflicts. For the third model, the crossing conflicts were used to predict the possible angle crashes per year. Finally, the fourth model used rear end conflicts to predict potential rear end crashes.

The four models were applied to the three penetration levels: $0 \% \mathrm{AV}, 50 \% \mathrm{AV}$ and $100 \% \mathrm{AV}$ and by using Equation 1, crashes were predicted. Table 8 compares the mean of crashes per year calculated for each model at various penetration levels.

As can be seen, the highest mean value for total, injury and rear end crashes occurs at a $0 \% \mathrm{AV}$ penetration level (no automated vehicles). As the automated vehicles start to be introduced to the simulated intersections, the mean value for crashes per year starts to decrease (for all types of crashes). Finally, at the $100 \%$ AV level, the lowest mean value is captured for all the crash types, except angle crashes. However, this change is negligible and unlikely to be of statistical significance due to randomness in the simulation process. 
Table 8: Mean crashes per year at various penetration levels

\begin{tabular}{|c|c|c|c|c|}
\cline { 2 - 5 } \multicolumn{1}{c|}{} & \multicolumn{4}{|c|}{ Mean Values (Crashes/year) } \\
\hline Penetration Levels & $\begin{array}{c}\text { Total crashes using } \\
\text { total conflicts }\end{array}$ & $\begin{array}{c}\text { Injury crashes } \\
\text { using total conflicts }\end{array}$ & $\begin{array}{c}\text { Angle crashes using } \\
\text { crossing conflicts }\end{array}$ & $\begin{array}{c}\text { Rear end crashes } \\
\text { using rear end } \\
\text { conflicts }\end{array}$ \\
\hline $\mathbf{0 \%}$ & 33.94 & 7.42 & 5.36 & 10.60 \\
\hline $\mathbf{5 0 \%}$ & 25.66 & 5.81 & 5.30 & 7.64 \\
\hline $\mathbf{1 0 0 \%}$ & 24.74 & 5.62 & 5.37 & 7.23 \\
\hline
\end{tabular}

Another observation from Table 8 is the fact that there is a significant reduction of crashes from $0 \% \mathrm{AV}$ to $50 \% \mathrm{AV}$; yet the difference in crashes from $50 \% \mathrm{AV}$ to $100 \% \mathrm{AV}$ is much lower. Results for individual estimates of crashes at each penetration level are given in the appendix. 


\section{Crash Modification Factors (CMFs) for Introducing AVs}

This chapter will explain and discuss the results obtained for the CMFs for introducing automated vehicles.

Once the crashes were predicted using the four crash prediction models (for all penetration levels), it was possible to calculate the crash modification factors. These factors show the effect of introducing $\mathrm{AVs}$ on the simulated intersections in comparison to the current state with $0 \% \mathrm{AV}$.

To begin with, the CMF was calculated for each intersection for all four crash prediction models. The crash modification factor reflects the expected change in crashes when $50 \% \mathrm{AV}$ and $100 \% \mathrm{AV}$ are introduced. Subsequently, an average CMF of all intersections was calculated for each model based on the average number of crashes at the three penetration levels. This step was performed to be able to compare the results obtained.

Table 9 summarizes crash modification factors after applying both countermeasures, i.e., 50\% AV and $100 \% \mathrm{AV}$, as well as the potential reduction in crashes for each scenario.

Table 9: Summary of CMFs by crash model

\begin{tabular}{|c|c|c|c|c|}
\hline MODEL & $\begin{array}{c}\text { CMF at } \\
\mathbf{5 0 \%} \mathbf{A V}\end{array}$ & $\begin{array}{c}\text { CMF at } \\
\mathbf{1 0 0 \%} \mathbf{A V}\end{array}$ & $\begin{array}{c}\text { Reduction in } \\
\text { crashes for } \\
\mathbf{5 0 \%}\end{array}$ & $\begin{array}{c}\text { Reduction in } \\
\text { crashes for } \\
\mathbf{1 0 0 \%} \mathbf{A V}\end{array}$ \\
\hline $\begin{array}{c}\text { Total Crashes using } \\
\text { Total Conflicts }\end{array}$ & 0.76 & 0.73 & $24.4 \%$ & $27.1 \%$ \\
\hline $\begin{array}{c}\text { Injury Crashes using } \\
\text { Total Crashes }\end{array}$ & 0.78 & 0.76 & $21.7 \%$ & $24.2 \%$ \\
\hline $\begin{array}{c}\text { Angles Crashes using } \\
\text { Crossing Conflicts }\end{array}$ & 0.99 & 1.00 & $1.2 \%$ & $0 \%$ \\
\hline $\begin{array}{c}\text { Rear-end Crashes } \\
\text { using Rear-end } \\
\text { Conflicts }\end{array}$ & 0.72 & 0.68 & $27.9 \%$ & $31.8 \%$ \\
\hline
\end{tabular}

From the results displayed above, it can be observed that implementing automated vehicles at the 78 signalized intersections will potentially reduce crashes. At a 50\%AV penetration level, all types of crashes presented a CMF below one. This means that there is a possible reduction in estimated crashes. However, it is important to stress the fact that in this study the driving behaviour of nonautomated vehicles is ideal and complies with the traffic rules. 
Based on a report from the United Kingdom on the integration of AVs and HDV (human driven vehicles), when crossing a junction, drivers of non-automated vehicles would base their decision on gap size and speed of the incoming vehicle - aware that the approaching vehicle was an AV (TRL Limited, 2017). At the same time, it was found that under a higher volume of AVs, drivers of non-automated vehicles felt more comfortable performing certain maneuvers, such as overtaking. This supports the idea that under mixed traffic conditions, non-automated vehicles would change their driving behaviour while still obeying the rules of the road. Nevertheless, this simulation does not account for undesired behaviour from non-automated vehicle drivers. A prime example of this can be exhibited in the recent crash of an automated Uber vehicle with a nonautomated vehicle that was caused when the driver of the non-automated vehicle failed to yield the way to the automated Uber car (CBC News, 2017).

At a penetration level of $100 \% \mathrm{AV}$, total, injury and rear-end crashes showed a CMF below one, representing a reduction in crashes. However, the $\mathrm{CMF}$ calculated for angle crashes shows a value of one, which defines no change after the countermeasure was applied.

As mentioned in chapters 5 and 6, the change in conflicts and predicted crashes from 50\% AV to $100 \% \mathrm{AV}$ has been marginal. As previously mentioned, this could be indicative of a change in driving behaviour from the non-automated vehicles. At the same time, this could be due to the connectivity needed for AVs with the infrastructure. Once all the vehicles on the road are automated (having at least a level 3 automation), improvements to the infrastructure will be necessary for them to excel in their performance. Since the simulation in this research study does not account for V2I, it can be assumed that automated vehicles will not be expected to portray their best performance.

Finally, it is important to mention that after having the CMFs for both countermeasures, graphs plotting the CMFs versus crashes, conflicts types and AADT (Annual Average Daily Traffic) were prepared in order to evaluate the correlation of these factors to the crash modification factors. These graphs were developed for each of the crash prediction models used, however, results obtained were not revealing of any interesting trends. 


\section{Crash Modification Factors for a Safety Treatments in the Presence of AVs}

This section aims to explore the effects on signalized intersections with various penetration levels of automated vehicles when applying two safety treatments - changing from permissive left turn phasing to permissive-protected and adding an exclusive left turn. The motivation for these treatments is based on a previous study by Saleem (2012) in which the first safety treatment was applied to similar signalized intersections to analyze its effects on crossing conflicts and its respective crashes. Additionally, a key motivation in this study is to explore how these effects would differ in the presence of automated vehicles.

\subsection{Safety Treatment: Left turn phasing improvement}

A permissive left turn requires all left turns to be done through gaps in oncoming traffic. However, a permissive-protected left turn phase provides an initial safe unopposed protected left turns, followed by regular permissive left turns.

Per Saleem (2012), the criteria used for selecting the 13 intersections to which the hypothetical treatment was applied to are described below:

- Must have at least one exclusive left turn at any approach

- Should have a level of service of C, D, E or F (where A and F represent the best and worst quality of traffic service, respectively)

- Traffic volumes for left turns should be 50 vehicles per hour or higher

Of the 13 signalized intersections chosen, 2 approaches were treated at 3 intersections, 3 approaches were treated at 1 intersection and 4 approaches were treated at 9 intersections.

The sections below describe and discuss findings for the application of this safety treatment.

\subsubsection{Simulation and Conflict Analysis}

Similar steps described in Section 5 were performed to run the simulations of this safety treatment. Once the 10 runs for each intersection were completed in VISSIM, the outputs were exported to SSAM. Tables 10, 11 and 12 outline the results obtained before and after the treatment was applied to the intersections at various penetration levels. 
Table 10: Comparison of conflicts at $0 \% A V$

\begin{tabular}{|c|c|c|c|}
\hline Conflict Type - 0\%AV & $\begin{array}{c}\text { Total Number of } \\
\text { Conflicts BEFORE }\end{array}$ & $\begin{array}{c}\text { Total Number of } \\
\text { Conflicts AFTER }\end{array}$ & \% Change \\
\hline TOTAL & 22757 & 8667 & $61.92 \%$ \\
\hline CROSSING & 1333 & 993 & $25.51 \%$ \\
\hline LANE CHANGE & 1408 & 614 & $56.39 \%$ \\
\hline REAR END & 20016 & 7060 & $64.73 \%$ \\
\hline
\end{tabular}

Table 11: Comparison of conflicts at 50\% AV

\begin{tabular}{|c|c|c|c|}
\hline Conflict Type - 50\%AV & $\begin{array}{c}\text { Total Number of } \\
\text { Conflicts BEFORE }\end{array}$ & $\begin{array}{c}\text { Total Number of } \\
\text { Conflicts AFTER }\end{array}$ & \% Change \\
\hline TOTAL & 7874 & 7518 & $4.52 \%$ \\
\hline CROSSING & 970 & 1075 & $-10.82 \%$ \\
\hline LANE CHANGE & 707 & 530 & $25.04 \%$ \\
\hline REAR END & 6197 & 5913 & $4.58 \%$ \\
\hline
\end{tabular}

Table 12: Comparison of conflicts at 100\%AV

\begin{tabular}{|c|c|c|c|}
\hline Conflict Type - 100\%AV & $\begin{array}{c}\text { Total Number of } \\
\text { Conflicts BEFORE }\end{array}$ & $\begin{array}{c}\text { Total Number of } \\
\text { Conflicts AFTER }\end{array}$ & \% Change \\
\hline TOTAL & 5967 & 4950 & $17.04 \%$ \\
\hline CROSSING & 1104 & 1142 & $-3.44 \%$ \\
\hline LANE CHANGE & 647 & 420 & $35.09 \%$ \\
\hline REAR END & 4216 & 3388 & $19.64 \%$ \\
\hline
\end{tabular}

From the results, it can be observed that the addition of the permissive-protected left turn has decreased the possible number of conflicts for all three scenarios. At a $0 \% \mathrm{AV}$ penetration level, the average number of conflicts will be reduced by approximately $52 \%$.

For a $50 \%$ penetration level of $\mathrm{AVs}$, the reduction in conflicts is not as distinguished as those in the $0 \% \mathrm{AV}$; there even seems to be a slight increase of $10 \%$ for the crossing conflicts. This could be caused by the mixed traffic and the combination of different driving behaviours within the same road. 
Finally, at $100 \% \mathrm{AV}$, the percent change of conflicts for all conflict types seems to be reduced in comparison to the $50 \% \mathrm{AV}$ penetration level. In this case, all the vehicles are expected to have a similar and uniform driving behaviour on the roads. Although crossing conflicts are still increasing after the safety treatment is applied, there is a reduction in conflicts of approximately $6 \%$ by moving from a $50 \%$ to $100 \%$ penetration level of automated vehicles.

Even though the change in conflicts is not uniform throughout all three penetration levels, the results show a potential benefit for total, lane change and rear end conflicts. The increase in possible number crossing conflicts is further addressed in the following sections.

\subsubsection{Crash Prediction Before and After Safety Treatment}

After analyzing conflicts obtained, crashes were predicted for the 13 signalized intersections before and after the safety treatment at the three penetration levels. The crash types were predicted using the crash prediction models developed by Saleem (2012), which can be referred to in Table 4. The combinations used for crash predictions were as follows:

- Total crashes using total conflicts

- Angle crashes using crossing conflicts

- Rear end crashes using rear end conflicts

- Side swipe crashes using lane change conflicts

- Turning crashes using crossing conflicts

- Injury crashes using total conflicts

The study by Saleem (2012) used five models, while this study uses six models. The last combination was added to show that with the introduction of AVs injury crashes may be especially reduced.

Tables 13 and 14 provide a summary of predicted crashes before and after the left turn phasing was changed from permissive to permissive-protected. 
Table 13: Predicted crashes per year BEFORE safety treatment

\begin{tabular}{|l|c|c|c|}
\hline \multirow{2}{*}{$\begin{array}{c}\text { Crash } \\
\text { Type }\end{array}$} & \multicolumn{3}{|c|}{ PREDICTED CRASHES BEFORE TREATMENT } \\
\cline { 2 - 4 } & $\mathbf{0 \% A V}$ & $\mathbf{5 0 \% A V}$ & $\mathbf{1 0 0 \% \mathbf { A V }}$ \\
\hline Total & 478.01 & 335.58 & 302.66 \\
\hline Angle & 71.09 & 63.62 & 64.72 \\
\hline Rear end & 150.78 & 102.20 & 89.19 \\
\hline $\begin{array}{l}\text { Side } \\
\text { swipe }\end{array}$ & 56.52 & 47.38 & 45.46 \\
\hline Turning & 72.16 & 63.06 & 64.50 \\
\hline Injury & 103.86 & 76.19 & 69.57 \\
\hline
\end{tabular}

Table 14: Predicted crashes per year AFTER safety treatment

\begin{tabular}{|l|c|c|c|}
\hline \multirow{2}{*}{$\begin{array}{c}\text { Crash } \\
\text { Type }\end{array}$} & \multicolumn{3}{|c|}{ PREDICTED CRASHES AFTER TREATMENT } \\
\cline { 2 - 4 } & $\mathbf{0 \% A V}$ & $\mathbf{5 0 \% \mathbf { A V }}$ & $\mathbf{1 0 0 \% \mathbf { A V }}$ \\
\hline Total & 340.66 & 324.85 & 280.38 \\
\hline Angle & 62.93 & 64.36 & 65.40 \\
\hline Rear end & 104.72 & 98.94 & 81.37 \\
\hline $\begin{array}{l}\text { Side } \\
\text { swipe }\end{array}$ & 45.76 & 43.42 & 40.77 \\
\hline Turning & 62.38 & 64.11 & 65.40 \\
\hline Injury & 77.21 & 74.07 & 65.08 \\
\hline
\end{tabular}

Similar to the results of conflicts described in Section 8.1, the predicted crashes after the treatment are reduced for the majority of the crash types at the three penetration levels. There is a slight increase in turning and angle crashes for the $50 \% \mathrm{AV}$ and $100 \% \mathrm{AV}$, but this is negligible and inconsequential. As previously mentioned, this could be attributed to randomness in the simulation process.

\subsubsection{Crash Modification Factors for Left Turn Phasing Improvement}

The crash modification factors were calculated by using the predicted crashes for the before and after scenario. The results are summarized in Table 15. 
Table 15: Estimated CMFs for safety treatment

\begin{tabular}{|l|c|c|c|}
\hline \multirow{2}{*}{$\begin{array}{c}\text { Crash } \\
\text { Type }\end{array}$} & \multicolumn{3}{|c|}{ AVERAGE CMF (SAFETY TREATMENT) } \\
\cline { 2 - 4 } & $\mathbf{0 \%} \mathbf{A V}$ & $\mathbf{5 0 \% \mathbf { A V }}$ & $\mathbf{1 0 0 \% \mathbf { A V }}$ \\
\hline Total & 0.71 & 0.97 & 0.93 \\
\hline Angle & 0.89 & 1.01 & 1.01 \\
\hline Rear end & 0.69 & 0.97 & 0.91 \\
\hline $\begin{array}{l}\text { Side } \\
\text { swipe }\end{array}$ & 0.81 & 0.92 & 0.90 \\
\hline Turning & 0.86 & 1.02 & 1.01 \\
\hline Injury & 0.74 & 0.97 & 0.94 \\
\hline
\end{tabular}

The CMFs for the majority of crash types and at all three penetration levels have a value below 1. As explained in Section 3.4, this represents an expected decrease in crashes. These results are consistent with the outcomes found in Section 8.1 and Section 8.2, where the expected conflicts and crashes after applying the safety treatment were potentially reduced.

The highlighted cells represent CMF values equal or higher than 1, meaning the expected number of crashes will increase if the safety treatment is applied. It is important to notice that the highlighted cells, though inconsequential, are present during the introduction of automated vehicles at the signalized intersections. This supports the general observation from Table 15 that the benefits of this treatment, though substantial with no AVs, diminish in the presence of AVs.

For the $100 \% \mathrm{AV}$ penetration level, CMFs higher than 1 were obtained for angle and turning crashes. One of the main reasons for these results could be ascribed to a driver regaining control of the vehicle's system. Based on a driving simulator study about drivers resuming control from a level 3 automated vehicle, it was found that "it took drivers approximately 35-40 seconds to stabilize their lateral control of the vehicle" (Merat, Jamson, Lai, Daly, \& Carsten, 2013). Despite applying the safety treatment by changing the left turn phasing to permissive-protected, this time span is enough to be a probable cause of a crash at the intersection.

For the 50\%AV penetration level, the same crash types (angle and turning) display a CMF of 1 or higher. The principal issue that could be causing these results after implementing the safety treatment could be attributed to the mixed traffic of automated and non-automated vehicles. Based 
on a paper from the Massachusetts Institute of Technology (MIT), AVs are known to wait for very long gaps to finally make the turn (Leonard, et al., 2008). Until the system does not find what it considers a safety margin, it will not perform the turning maneuver. On the other hand, drivers of non-automated vehicles will adjust their driving strategy as the crossing opportunities (gaps) change. Unlike the fixed safety margin for automated vehicles, the safety margin managed by human drivers is constantly switching for every situation.

Nevertheless, the CMF values obtained for 50\%AV and 100\%AV penetration are very close to 1. Thus, the general effect of changing a left turn phasing is negligible under the presence of automated vehicles. This could be attributed to the fact that introducing AVs can be considered a safety treatment by itself to signalized intersections. Additionally, these results could be due to randomness in the simulation process.

The study by Saleem (2012) used very similar intersections to explore the effects of adding the permissive-protected phasing for $0 \% \mathrm{AV}$ penetration. Comparable to those results, it can be seen that the outcomes for predicted crashes do decrease when this safety treatment is applied. Table 16 displays the comparison of CMF values.

Table 16: Comparison of calculated CMFs to those obtained from Saleem (2012)

\begin{tabular}{|c|c|c|}
\hline \multirow[b]{2}{*}{$\begin{array}{l}\text { Crash } \\
\text { Type }\end{array}$} & \multicolumn{2}{|c|}{ CMF AT 0\%AV (SAFETY TREATMENT) } \\
\hline & $\begin{array}{l}\text { AVERAGE CMF BY } \\
\text { Saleem (2012) }\end{array}$ & $\begin{array}{c}\text { AVERAGE CMF } \\
\text { CALCULATED IN THIS } \\
\text { STUDY }\end{array}$ \\
\hline Total & 0.83 & 0.71 \\
\hline Angle & 0.82 & 0.89 \\
\hline Rear end & 0.83 & 0.69 \\
\hline $\begin{array}{l}\text { Side } \\
\text { swipe } \\
\end{array}$ & 0.85 & 0.81 \\
\hline Turning & 0.79 & 0.86 \\
\hline
\end{tabular}

As it can be observed from Table 16, the calculated average CMFs in this study for 0\%AV penetration level, and those in the study by Saleem (2012), show a value below 1 and represent a potential decrease in crashes. In addition, it is important to mention that the values obtained in both studies are not the same. This may be caused by the difference in signalized intersections used, as the effects on conflicts and crashes vary from intersection to intersection. 
Similar results were obtained from an empirical Bayes before-after study conducted by Srinivasan et al (2012) for 55 intersections in the city of Toronto, in which the left turn was changed to protected-permissive. In Srinivasan et al. study, CMF values were found to be approximately 0.86 with a $5 \%$ standard error.

\subsection{Safety Treatment: Introduction of Exclusive Left Turn}

This safety treatment consisted of the hypothetical introduction of a left turn lane to selected signalized intersections to explore its safety effects under the presence of AVs. This safety treatment was applied to 11 of the 78 signalized intersections by changing a shared through and left lane to through only and adding an exclusive left turn lane. The main criterion used to identify the 11 intersections was that the current level of service and the traffic volume warranted the addition of the left turn lane. Once again, this criterion is based on the study by Saleem (2012) that was performed to similar intersections, but not under the presence of AVs.

Similar steps, as described in Section 8.1, were performed to obtain the possible number of conflicts and estimate potential crashes. Table 17 summarizes before and after estimated crashes, as well as crash modification factor results at the three penetration levels.

Once again, it is possible to observe that at a $0 \% \mathrm{AV}$ penetration level, crashes are expected to be reduced. However, under the presence of AVs, the CMF values obtained - even though below one - suggest that the effects of the treatment diminish when compared to the 0\% AV scenario; similar to what was observed for the left turn phasing improvement. 
Table 17: Estimated crashes and average CMF for addition of exclusive left turn

\begin{tabular}{|c|c|c|c|c|c|c|c|c|c|}
\hline \multirow{3}{*}{$\begin{array}{c}\text { Crash } \\
\text { Type }\end{array}$} & \multicolumn{3}{|c|}{ 0\%AV Penetration } & \multicolumn{3}{|c|}{ 50\% AV Penetration } & \multicolumn{3}{|c|}{$100 \%$ AV Penetration } \\
\hline & \multicolumn{2}{|c|}{$\begin{array}{c}\text { Total } \\
\text { Predicted } \\
\text { Crashes/year }\end{array}$} & \multirow{2}{*}{$\begin{array}{l}\text { Average } \\
\text { CMF }\end{array}$} & \multicolumn{2}{|c|}{$\begin{array}{c}\text { Total } \\
\text { Predicted } \\
\text { Crashes/year } \\
\end{array}$} & \multirow{2}{*}{$\begin{array}{l}\text { Average } \\
\text { CMF }\end{array}$} & \multicolumn{2}{|c|}{$\begin{array}{l}\text { Total Predicted } \\
\text { Crashes/year }\end{array}$} & \multirow{2}{*}{$\begin{array}{c}\text { Average } \\
\text { CMF }\end{array}$} \\
\hline & Before & After & & Before & After & & Before & After & \\
\hline Total & 397.43 & 263.05 & 0.66 & 294.36 & 257.49 & 0.87 & 294.34 & 245.37 & 0.83 \\
\hline Angle & 62.30 & 52.37 & 0.84 & 59.95 & 54.14 & 0.90 & 61.05 & 53.71 & 0.88 \\
\hline Rear end & 119.48 & 76.73 & 0.64 & 84.30 & 74.79 & 0.89 & 83.39 & 70.78 & 0.85 \\
\hline Side swipe & 45.80 & 37.64 & 0.82 & 42.83 & 35.40 & 0.83 & 44.04 & 33.45 & 0.76 \\
\hline Turning & 61.67 & 49.83 & 0.81 & 58.89 & 51.95 & 0.88 & 60.32 & 51.42 & 0.85 \\
\hline Injury & 85.36 & 59.55 & 0.70 & 65.73 & 58.47 & 0.89 & 65.71 & 56.04 & 0.85 \\
\hline
\end{tabular}




\section{Summary, Conclusions and Future Research}

This chapter contains the overall review of this research study and its objectives, as well as conclusions derived from the results obtained. It then finalizes with recommendations for future research.

\subsection{Summary}

The main objective of this study was to analyze the safety at signalized intersections in the city of Toronto with and without the introduction of automated vehicles at three penetration levels: $50 \%$ and $100 \%$. Additionally, the individual effects of changing a left turn phasing to permissiveprotected, as well as introducing an exclusive left turn at $0 \% \mathrm{AV}, 50 \% \mathrm{AV}$ and $100 \% \mathrm{AV}$, were explored.

This goal was achieved by first making specific assumptions to the simulation of AVs as well as the scenario with $50 \%$ AV penetration. These assumptions were based on previous studies performed on automated vehicles, as well as recent information on the expected behaviour of these vehicles.

In overcoming these limitations, the objective was achieved by introducing a specific driving behaviour for AVs and simulating 78 4-legged signalized intersections using VISSIM software. The vehicle trajectories from the microsimulation were analyzed using the Surrogate Safety Assessment Model software (SSAM) to estimate conflicts as surrogate measures of safety. The conflicts (total, crossing, lane change and rear end) were then used to predict possible crashes per intersection at the three penetration levels using data and crash prediction models previously developed by Saleem (2012). Subsequently, these crashes were used to calculate the crash modification factors, which were used to compare expected number of crashes once automated vehicles were introduced, as well as the application of the safety treatments under the presence of AVs.

From the safety treatments performed at the three penetration levels, changes were applied to selected intersections. Similar to the steps taken before, a microsimulation and a safety evaluation were performed by obtaining new conflicts and predicting crashes for the altered intersections. In this case, six crash prediction models developed by Saleem (2012) were used to predict total, angle, 
rear end, side swipe, turning and injury crashes. Finally, new crash modification factors were calculated to compare results before and after applying individual safety treatments, quantifying the impact of AVs at signalized intersections with and without this treatment.

\subsection{Conclusions}

Ultimately, this study has shown that by introducing automated vehicles to signalized intersections, crashes will potentially be reduced. With respect to the base condition (0\%AV), at a $50 \%$ penetration level of AVs, total crashes were reduced up to $28 \%$. In addition, at a $100 \%$ penetration level of AVs, if achievable, crashes would be reduced up to $32 \%$.

Nevertheless, it is important to observe that the difference in crash reduction from having $50 \% \mathrm{AV}$ to $100 \% \mathrm{AV}$ is marginal. Due to the high technology connectivity needed for a $100 \% \mathrm{AV}$ penetration to work as expected (based on studies about the benefits of automated vehicles), it can be deduced that the lack of V2I connectivity in the simulation process could be a probable cause of not showing a higher reduction in crashes at $100 \% \mathrm{AV}$ penetration.

In regards to the first safety treatment applied, at a $0 \%$ penetration level of AVs, the introduction of a permissive-protected left turn phasing will potentially reduce total crashes up to $29 \%$. These results were reasonably comparable to those estimated in a study by Saleem (2012) and validated in a study by Srinivasan et al (2012) for very similar intersections. However, for 50\% and $100 \%$ $\mathrm{AV}$ penetration levels, the benefits of the safety treatment diminish considerably compared to that for $0 \% \mathrm{AVs}$. This suggests that the introduction of AVs has already acted as a safety treatment considering their longer wait for gaps when compared to non-automated vehicles.

Similarly, by applying the second safety treatment of introducing an exclusive left turn to selected intersections, it was also found that at a $0 \% \mathrm{AV}$ level, crashes were reduced. Once more, in the presence of AVs, the results are not as beneficial in comparison to those with $0 \%$ AVs. This finding, if verified for other site and treatment types, has considerable implications for the design of roads and development of safety treatments now and in the future. 


\subsection{Future Research}

The results obtained in this study still pose a few questions and open a couple of opportunities to expand and explore the safety of implementing ITS on road networks. Regarding automated vehicles, further studies can be developed for the specific driving behaviour in order to create a more accurate representation of these new transportation additions. This improvement could be potentially achieved by creating a specific car-following model for automated vehicles, which will allow the vehicle to automatically maintain a minimum acceptable distance from the vehicle in front. However, it is imperative to take into consideration that to evaluate the influence of AVs on the roads, non-automated vehicles must be included in all scenarios.

It is also of importance to continue to explore safety effects under mixed traffic. As time progresses, it is more likely to reach a scenario in which there are different percentages of AVs combined with non-automated vehicles. An example for future research is the addition of other penetration levels, such as $25 \% \mathrm{AV}$ and $75 \% \mathrm{AV}$.

Regarding types of crashes explored in this study, further research could investigate the expected fatal injury and non-fatal injury crashes. This could possibly demonstrate that adding automated vehicles to signalized intersections would have an impact on treating the most severe crashes.

Finally, further research in safety treatments with automated vehicles at various penetration levels should be studied more in depth. In this study, a marginal change was observed when changing the left turn phase to a permissive-protected phasing, as well as adding an exclusive left turn lane. It was suspected that applying a safety treatment, such as that for accommodating left turns, would be considered redundant; AVs already have a safety margin when making a left turn at an intersection.

Another scenario that could be analyzed is the effects on safety by separating mixed traffic (penetration level: 50\%) using designated lanes for automated and non-automated vehicles. Per Reich (2013), it is of importance to explore the potential benefits of exclusive lanes for vehicles equipped with this type of technology. The results obtained by applying this change could be comparable to the ones in this study in order to observe any changes in expected crashes. However, research on this specific area is necessary to be certain and accurate about why this behaviour occurs. 


\section{Appendices}

\section{Appendix A: Statistics of Predicted Crashes for Three Penetration Levels}

\begin{tabular}{|c|c|c|c|}
\hline $\begin{array}{c}\text { Predicted Crashes - } \\
\text { 0\%AV }\end{array}$ & Mean & Minimum & Maximum \\
\hline $\begin{array}{c}\text { Total crashes using } \\
\text { total conflicts }\end{array}$ & 26.20 & 19.45 & 30.67 \\
\hline $\begin{array}{c}\text { Injury crashes using } \\
\text { total conflicts }\end{array}$ & 5.94 & 4.53 & 6.82 \\
\hline $\begin{array}{c}\text { Angle crashes using } \\
\text { crossing conflicts }\end{array}$ & 4.84 & 2.47 & 6.77 \\
\hline $\begin{array}{c}\text { Rear end crashes } \\
\text { using rear end } \\
\text { conflicts }\end{array}$ & 8.06 & 5.35 & 10.16 \\
\hline
\end{tabular}

\begin{tabular}{|c|c|c|c|}
\hline $\begin{array}{c}\text { Predicted Crashes - } \\
\mathbf{5 0 \% A V}\end{array}$ & Mean & Minimum & Maximum \\
\hline $\begin{array}{c}\text { Total crashes using } \\
\text { total conflicts }\end{array}$ & 24.99 & 19.64 & 29.53 \\
\hline $\begin{array}{c}\text { Injury crashes using } \\
\text { total conflicts }\end{array}$ & 5.70 & 4.67 & 6.62 \\
\hline $\begin{array}{c}\text { Angle crashes using } \\
\text { crossing conflicts }\end{array}$ & 4.95 & 2.59 & 6.79 \\
\hline $\begin{array}{c}\text { Rear end crashes } \\
\text { using rear end } \\
\text { conflicts }\end{array}$ & 7.61 & 5.63 & 9.55 \\
\hline
\end{tabular}




\begin{tabular}{|c|c|c|c|}
\hline $\begin{array}{c}\text { Predicted Crashes } \\
-\mathbf{1 0 0 \% A V}\end{array}$ & Mean & Minimum & Maximum \\
\hline $\begin{array}{c}\text { Total crashes } \\
\text { using total } \\
\text { conflicts }\end{array}$ & 21.57 & 16.73 & 27.13 \\
\hline $\begin{array}{c}\text { Injury crashes } \\
\text { using total } \\
\text { conflicts }\end{array}$ & 5.01 & 4.06 & 6.14 \\
\hline $\begin{array}{c}\text { Angle crashes } \\
\text { using crossing } \\
\text { conflicts }\end{array}$ & 5.03 & 2.47 & 6.85 \\
\hline $\begin{array}{c}\text { Rear end crashes } \\
\text { using rear end } \\
\text { conflicts }\end{array}$ & 6.26 & 4.61 & 8.18 \\
\hline
\end{tabular}


Appendix B: Comparison of Conflicts Before and After Safety Treatment

\begin{tabular}{|c|c|c|c|}
\hline Conflict Type - 100\%AV & $\begin{array}{c}\text { Total Number of } \\
\text { Conflicts BEFORE }\end{array}$ & $\begin{array}{c}\text { Total Number of } \\
\text { Conflicts AFTER }\end{array}$ & \% Change \\
\hline TOTAL & 5967 & 4950 & $17.04 \%$ \\
\hline CROSSING & 1104 & 1142 & $-3.44 \%$ \\
\hline LANE CHANGE & 647 & 420 & $35.09 \%$ \\
\hline REAR END & 4216 & 3388 & $19.64 \%$ \\
\hline
\end{tabular}

\begin{tabular}{|c|c|c|c|}
\hline Conflict Type - 50\%AV & $\begin{array}{c}\text { Total Number of } \\
\text { Conflicts BEFORE }\end{array}$ & $\begin{array}{c}\text { Total Number of } \\
\text { Conflicts AFTER }\end{array}$ & \% Change \\
\hline TOTAL & 7874 & 7518 & $4.52 \%$ \\
\hline CROSSING & 970 & 1075 & $-10.82 \%$ \\
\hline LANE CHANGE & 707 & 530 & $25.04 \%$ \\
\hline REAR END & 6197 & 5913 & $4.58 \%$ \\
\hline
\end{tabular}

\begin{tabular}{|c|c|c|c|}
\hline Conflict Type - 0\%AV & $\begin{array}{c}\text { Total Number of } \\
\text { Conflicts BEFORE }\end{array}$ & $\begin{array}{c}\text { Total Number of } \\
\text { Conflicts AFTER }\end{array}$ & \% Change \\
\hline TOTAL & 22757 & 8667 & $61.92 \%$ \\
\hline CROSSING & 1333 & 993 & $25.51 \%$ \\
\hline LANE CHANGE & 1408 & 614 & $56.39 \%$ \\
\hline REAR END & 20016 & 7060 & $64.73 \%$ \\
\hline
\end{tabular}




\section{Appendix C: CMF Ranges After Applying Safety Treatment}

\begin{tabular}{|l|c|c|c|}
\hline \multirow{3}{*}{ Crash Type } & \multicolumn{2}{|c|}{$\begin{array}{c}\text { CMF RANGES (SAFETY } \\
\text { TREATMENT) }\end{array}$} & \multirow{2}{*}{$\begin{array}{c}\text { AVERAGE } \\
\text { CMF }\end{array}$} \\
\cline { 2 - 3 } & \multicolumn{2}{|c|}{ 0\%AV } & \\
\cline { 2 - 3 } & Minimum & Maximum & 0.71 \\
\hline Total & 0.555 & 0.824 & 0.89 \\
\hline Angle & 0.548 & 1.216 & 0.69 \\
\hline Rear end & 0.545 & 0.786 & 0.81 \\
\hline Side swipe & 0.566 & 1.027 & 0.86 \\
\hline Turning & 0.477 & 1.274 & 0.74 \\
\hline Injury & 0.597 & 0.844 & \\
\hline
\end{tabular}

\begin{tabular}{|l|c|c|c|}
\hline \multirow{2}{*}{ Crash Type } & \multicolumn{2}{|c|}{ CMF RANGES (SAFETY } & \multirow{2}{*}{ TREATMENT) } \\
\cline { 2 - 3 } & \multicolumn{2}{|c|}{ AV\%AV } & \\
\cline { 2 - 3 } & Minimum & Maximum & \\
\hline Total & 0.825 & 1.089 & 0.97 \\
\hline Angle & 0.893 & 1.083 & 1.01 \\
\hline Rear end & 0.842 & 1.115 & 0.97 \\
\hline Side swipe & 0.720 & 1.079 & 0.92 \\
\hline Turning & 0.873 & 1.104 & 1.02 \\
\hline Injury & 0.845 & 1.079 & 0.97 \\
\hline
\end{tabular}

\begin{tabular}{|l|c|c|c|}
\hline \multirow{2}{*}{ Crash Type } & \multicolumn{2}{|c|}{$\begin{array}{c}\text { CMF RANGES (SAFETY } \\
\text { TREATMENT) }\end{array}$} & \multirow{2}{*}{$\begin{array}{c}\text { AVERAGE } \\
\text { CMF }\end{array}$} \\
\cline { 2 - 3 } & \multicolumn{2}{|c|}{ 100\%AV } & \\
\cline { 2 - 3 } & Minimum & Maximum & 0.93 \\
\hline Total & 0.780 & 1.122 & 1.01 \\
\hline Angle & 0.907 & 1.090 & 0.91 \\
\hline Rear end & 0.706 & 1.159 & 0.90 \\
\hline Side swipe & 0.716 & 1.022 & 1.01 \\
\hline Turning & 0.886 & 1.113 & 0.94 \\
\hline Injury & 0.804 & 1.107 & \\
\hline
\end{tabular}




\section{References}

Althoff, M., Stursberg, O., \& Buss, M. (2009, September 20). Model-Based Probabilistic Collision Detection in Autonomous Driving. IEEE Transactions on Intelligent Transportation Systems (Volume 10, Issue 2) (pp. 299-310). IEEE.

Aria, E. (2016). Investigation of automated vehicle effects on driver's behavior and traffic performance. Norrköping: Linköping University.

Bierstedt, J., Gooze, A., Gray, C., Peterman, J., Raykin, L., \& Walters, J. (2014). Effects of nextgeneration vehicles on travel demand and highway capacity. Princeton: ORFE.

CBC News. (2017, March 27). Uber resumes self-driving cars after accident in Arizona. Tempe, Arizona, United States of America.

City of Toronto. (2013, December 31). Transportation: Road Safety Plan. Retrieved from City of Toronto:

http://www1.toronto.ca/City\%200f\%20Toronto/Transportation\%20Services/Road\%20sa fety/Files/pdf/FATAL2013dec.pdf

FHWA. (2008, May). Safety: Surrogate Safety Assessment Model (SSAM). Retrieved from Federal Highway Administration Research and Technology: https://www.fhwa.dot.gov/publications/research/safety/08049/

Fuller, R. (2004). Towards a General Theory of Driver Behaviour. Dublin: Elsevier.

Gettman, D., Pu, L., Sayed, T., \& Shelby, S. (2008). Surrogate Safety Assessment Model and Validation. Final Report. Virginia: FHWA. Retrieved from FHWA.

Glauz, W. D., \& Migletz, D. J. (1980). Application of traffic conflict analysis at intersections. Washington: Transportation Research Board.

Gross, F., Persaud, B., \& Lyon, C. (2010). A Guide to Developing Quality Crash Modification Factors. Washington: FHWA.

Hallmark, S., \& Hawkins, N. (2014). Adding Turn Lanes/Channelization. Ames: Iowa Department of Transportation. 
Hayes, B. (2011). Leave the Driving to it. American Scientist, 362-366.

Hydén, C. (1987). The development of a method for traffic safety evaluation: The Swedish Traffic Conflicts Technique. Sweden: Bulletin Lund Institute of Technology Department .

ITS Canada. (2012). About us: Overview. Retrieved from ITS Canada: https://www.itscanada.ca/about/index/index.html

KPMG. (2012). Self-driving cars: The next revolution. University of Washington. Retrieved from University of Washington: https://faculty.washington.edu/jbs/itrans/self_driving_cars[1].pdf

Kun, L., \& Petros, I. (2004). Modeling of Traffic Flow of Automated Vehicles. IEEE TRANSACTIONS ON INTELLIGENT TRANSPORTATION SYSTEMS.

Leonard, J., How, J., Teller, S., Berger, M., Campbell, S., Fiore, G., . . Walter, M. (2008). A Perception-Driven Autonomous Urban Vehicle. Cambridge: Wiley Periodicals Inc.

Merat, N., Jamson, A. H., Lai, F. C., Daly, M., \& Carsten, O. M. (2013). Transition to manual: Driver behaviour when resuming control from a highly automated vehicle. Leeds: Elsevier.

NCHRP. (2004). A Guide for Reducing Collisions at Signalized Intersections. Washington: Transportation Research Board.

NHTSA. (2010, September). Distracted Driving 2009: NHTSA CrashStats. Retrieved from NHTSA CrashStats: https://crashstats.nhtsa.dot.gov/Api/Public/ViewPublication/811379

NHTSA. (2013). Preliminary Statement of Policy Concerncing Automated Vehicles. Washington: NHTSA.

Parker Jr, M. R., \& Zeeger, C. (1989). Traffic Conflict Techniques for Safety and OperationsObservers Manual. Virginia: FHWA.

PTV. (2011). Vissim 5.30-05 User Manual. Karlsruhe, Germany.

Reich, S. (2013). Automated and Autonomous Vehicles and Managed Lanes. Tampa: Center for Urban Transportation Research. 
Rosekind, M. R. (2016, December 12). About NHTSA: Remarks at Federal Automated Vehicles Policy public workshop. Retrieved from NHTSA: https://one.nhtsa.gov/AboutNHTSA/Presentations-\&-Speeches/mr_av_policy_public_workshop_12122016

Saleem, T. (2012). Evaluation of the Predictive Capabilities of Simulated Peak Hour Conflict Based Crash Prediction Models. Toronto: Ryerson University.

Saleem, T., Persaud, B., Shalaby, A., \& Ariza, A. (2014). Can Microsimulation Be Used to Estimate Intersection Safety? Transportation Research Board, 142-148.

Schoettle, B., \& Sivak, M. (2015). A Preliminary Analysis of Real-World Crashes Involving SelfDriving Vehicles. Ann Arbor: University of Michigan- Transportation Research Institute.

Shahdah, U., Saccomanno, F., \& Persaud, B. (2014). Integrated traffic conflict model for estimating crash modification factors. Toronto: Elsevier.

Souleyrette, R., \& Hochstein, J. (2012). Development of a Conflict Analysis Methodology Using SSAM. Ames: Iowa Department of Transportation.

Srinivasan, R., Lyon, C., Persaud, B., Baek, J., Gross, F., Smith, S., \& Sundstrom, C. (2012). Crash Modification Factors for Changes to Left-Turn Phasing. Transportation Research Record: Journal of the Transportation Research Board, 108-117.

Stewart, J., \& Al-Kaisy, A. (2001). New approach for developing warrants of protected left-turn phase at signalized intersections. Kingston: Pergamon.

Svensson, Å. (1998). A method for analysing the traffic process in a safety prespective. Sweden: Lund University.

Thiffault, P. (2011). Addressing Human Factors in the Motor Carrier Industry in Canada. CCMTA.

Thompson, H. T., \& Perkins, D. D. (1983). SURROGATE MEASURES FOR ACCIDENT EXPERIENCE AT RURAL ISOLATED HORIZONTAL CURVES. Washington: Transportation Research Board. 
Ticoll, D. (2015). Driving changes: Automated vehicles in Toronto. Toronto: University of Toronto. Retrieved from https:/www.schlegelundpartner.com/de/news/man-andmachine-automated-driving-legal-and-liability-hurdles/u/1124/

Trafficware. (2016). About: Synchro Studio. Retrieved from Trafficware: http://www.trafficware.com/synchro.html

Transport Canada. (2011, March). Motor Vehicle Safety: Road Safety in Canada. Retrieved from Transport Canada: https://www.tc.gc.ca/media/documents/roadsafety/tp15145e.pdf

Treat, J., Tumbas, N., McDonald, S., Shinar, D., Hume, R., Mayer, R., . . Castellan, N. (1979). Tri-level Studyf of the Causes of Traffic Accidents: Final Report. Washington: DOT.

TRL Limited. (2017). Published GATEway Project-Report PPR807. TRL Limited.

U.S. Department of Transportation. (2013, May 30). Briefing Room: U.S. Department of Transportation Releases Policy on Automated Vehicle Development. Retrieved from U.S. Department of Transportation: https://www.transportation.gov/briefing-room/usdepartment-transportation-releases-policy-automated-vehicle-development 